\title{
Exogenous vs. Endogenous Separation
}

\author{
Garey Ramey*
}

December 2007

\begin{abstract}
This paper assesses how various approaches to modelling the separation margin affect the ability of the Mortensen-Pissarides job matching model to explain key facts about the aggregate labor market. Allowing for realistic time variation in the separation rate, whether exogenous or endogenous, greatly increases the unemployment variability generated by the model. Specifications with exogenous separation rates, whether constant or time-varying, fail to produce realistic volatility and productivity comovement of the separation rate and worker flows. Specifications with endogenous separation rates, on the other hand, succeed along these dimensions. In addition, the endogenous separation model with on-the-job search yields a realistic Beveridge curve correlation. All of the specifications generate insufficient volatility of the job finding rate, vacancies and market tightness when calibrated in a standard manner. The latter deficiencies are remedied when the Hagedorn-Manovskii calibration is used, and the on-the-job search model, in particular, performs well along nearly all dimensions considered.
\end{abstract}

\footnotetext{
${ }^{*}$ University of California San Diego. Email: gramey@ucsd.edu. Web page: http://www.econ.ucsd.edu/ gramey. I would like to thank Shigeru Fujita, Bob Hall, Dale Mortensen, Mike Owyang and Valerie Ramey for helpful conversations.
} 


\section{Introduction}

In its complete form, the Mortensen-Pissarides job matching model (henceforth MP model) endogenously determines both the match creation and separation margins. ${ }^{1}$ While researchers agree that match creation is appropriately viewed as endogenous, there is little consensus as to the proper treatment of the separation margin. Papers such as Cole and Rogerson (1999), Fujita (2003, 2004), Mortensen and Pissarides (1994), Pissarides (2007) and others allow match dissolution to be responsive to incentives facing the worker and firm. On the other hand, Costain and Reiter (2006), Fujita and Ramey (2007), Hagedorn and Manovskii (forthcoming), Hall (2005), Hornstein, et al. (2006), Mortensen and Nagypál (2007), Shimer (2005), Yashiv (2006) and others specify that matches break up at a rate that is exogenous and constant, affected by neither incentives nor cyclical factors. Shimer (2005), Mortensen (2005), Mortensen and Nagypál (2007) and Yashiv (2006) consider a third possibility, namely that separation rates vary over time in an random manner, while Mortensen (1994, 2005), Krause and Lubik (2006), Pissarides (1994), Tasci (2006), Nagypál (2005a,b) and others allow for separation directly to new jobs.

This paper assesses how these various approaches to modeling the separation margin affect the ability of the MP model to explain key facts about unemployment, transition rates, worker flows and other variables. A discrete-time version of Pissarides' (2000) specification is calibrated at weekly frequency. Match separation is parameterized in four ways: (i) constant separation rate; (ii) exogenous separation rate following an $\mathrm{AR}(1)$ process; (iii) endogenous separation rate without on-the-job (OTJ) search; and (iv) endogenous separation rate with OTJ search. For the two specifications with endogenous separation, match-specific productivity factors follow a persistent stochastic process, i.e., the factors are not required to be i.i.d. over time, as in many previous papers. The model is solved using a nonlinear method that parameterizes match surplus and market tightness (i.e., the vacancy-unemployment ratio) on a grid, and iterates backward to exploit stability of the backward dynamics.

In calibrating the model, the values of the workers' unemployment benefit and bargaining weight, as well as the elasticity parameter of the matching function, are set to standard values advocated by Mortensen and Nagypál (2007). The calibration of the vacancy posting cost draws on survey evidence from Barron and Bishop (1985) and Barron,

\footnotetext{
${ }^{1}$ Throughout this paper, the terms "separation" and "job finding" denote movements of workers between employed and unemployed status.
} 
et al. (1997). Other parameters are chosen to match the mean monthly job finding and separation rates calculated by Fujita and Ramey (2006), who consider Current Population Survey data over the 1976-2005 period. In addition, each of the three specifications with time-varying separation rates is calibrated to match the standard deviation of the separation rate observed in the Fujita-Ramey data.

Statistics calculated from simulated data for the four specifications are compared to corresponding statistics obtained from the Fujita-Ramey data. The results show, first of all, that the model with constant separation rates fares poorly in accounting for the volatility of key labor market variables. It does not, of course, explain the substantial variability of the separation rate observed in the data; nor does it generate anywhere near the empirical volatility of unemployment, a point stressed by Costain and Reiter (2006) and Shimer (2005). In addition, the variability of gross worker flows, both unemployment-toemployment (UE) and employment-to-unemployment (EU), is far too low in the constant separation rate model.

On the other hand, the three specifications with time-varying separation rates, which are calibrated to match the volatility of the empirical separation rate, each generate substantially greater volatility of unemployment and worker flows. In the model with OTJ search, for example, the standard deviation of unemployment equals 60 percent of its empirical value. Moreover, the three specifications match closely the standard deviations of UE and EU flows. Introducing realistic variability at the separation margin thus substantially improves the performance of the MP model in accounting for unemployment and worker flow variability.

In the data, the separation rate and the two worker flow variables exhibit strong negative correlations with productivity. Both versions of the MP model with exogenous separation fail along this dimension, as they generate essentially no productivity comovement of separation rates and worker flows. The two versions with endogenous separation, however, exhibit realistic productivity comovement of these variables. Endogeneity of the separation rate appears central to explaining the cyclical properties of the separation rate and worker flows.

The two endogenous separation specifications differ in their ability to account for the Beveridge curve relationship, wherein unemployment and vacancies display strong negative correlation. In the absence of OTJ search, the model with endogenous separation produces a counterfactually positive unemployment-vacancy correlation, due to fact that higher unemployment makes workers easier to find during downturns, stimulating the posting 
of vacancies. With OTJ search, however, downturns also imply a fall in the number of employed searchers, militating against the rise in unemployment. The unemploymentvacancy correlation becomes strongly negative in this case, matching closely the empirical value. Thus, endogenous separation is consistent with the Beveridge curve relationship when OTJ search is added to the model.

In summary, the endogenous separation specification with OTJ search implies empirically reasonable volatility and comovement of unemployment, the separation rate and worker flows, along with a realistic Beveridge curve. Moreover, this specification captures the negative correlation between the job finding and separation rates seen in the data. Each of the remaining three specifications fails decisively along one or more of these dimensions. This provides strong support for the OTJ search model as the most valid specification.

The results also show, however, that the MP model under the standard calibration does not produce realistic volatility of the job finding rate, irrespective of how the separation margin is modelled. The empirical standard deviation of the job finding rate is nearly six times the simulated value for each of the four specifications. Similarly, the four specifications deliver insufficient volatility of vacancies and market tightness. This failure to generate volatility at the job finding margin, which lies at the heart of the Hall-Shimer critique of the MP model, is thus not resolved by introducing realistic behavior at the separation margin.

The MP model is further evaluated in terms of its ability to generate realistic dynamic interrelationships, as captured by cross correlations at various leads and lags. None of the four specifications reproduces the sluggish productivity responses of unemployment, the job finding rate, vacancies and market tightness that are seen in the data. As pointed out by Fujita and Ramey (2007), rapid adjustment of vacancies prevents the model from exhibiting realistic dynamics with respect to these variables. The OTJ search specification does, however, demonstrate empirically reasonable dynamic patterns along the other dimensions considered, including the cross correlations between unemployment and vacancies, and between job finding and separation rates.

Hagedorn and Manovskii (forthcoming) propose an alternative calibration strategy, drawing on empirical information on wages and profits, that raises the volatility of unemployment, market tightness and other variables in the constant separation rate model. To investigate the robustness of the current findings to this alternative, the constant separation rate and OTJ search specifications are suitably recalibrated. In line with Hagedorn 
and Manovskii's findings, this procedure yields much more realistic volatility of unemployment, the job finding rate, vacancies and market tightness. It does not, however, remedy the key failings of the constant separation rate model: in particular, the separation rate and worker flows continue to display unrealistic variability and productivity comovement. Under the new calibration, the OTJ search model performs well along nearly all dimensions considered.

Numerous previous papers have evaluated the properties of the MP model in dynamic stochastic equilibrium. Most closely related are Mortensen and Pissarides (1994) and Mortensen (1994). These papers calibrate and simulate endogenous separation versions of the standard MP model in continuous time, and stress the model's ability to explain facts about job creation and destruction in manufacturing. The latter paper also allows for OTJ search, and delivers countercyclical worker flows and a negative Beveridge correlation, consistent with the results obtained here.

More recently, Krause and Lubik (2006) and Tasci (2006) offer modifications of the MP model that incorporate OTJ search. ${ }^{2}$ Both papers show that their models yield significantly greater unemployment volatility than does the standard constant separate rate specification, and they also obtain negative Beveridge correlations.

Dynamic stochastic equilibrium versions of the MP model without OTJ search have been considered by Costain and Reiter (2006), Fujita (2003, 2004), Fujita and Ramey (2007), Hagedorn and Manovskii (forthcoming), Shimer (2005) and Yashiv (2006). These papers either specify exogenous separation rates, or else introduce endogenous separation by means of match-specific productivity factors that follow i.i.d. processes. In comparison to the preceding papers, the present one highlights the behavior of the separation margin and the various approaches to modelling it. It also allows for match-specific productivity persistence and OTJ search.

Finally, a number or papers have embedded the MP model into stochastic dynamic general equilibrium frameworks. ${ }^{3}$ This body of work focusses chiefly on dynamic propagation of aggregate technology and monetary shocks. An exception is Merz (1995), who

\footnotetext{
${ }^{2}$ Krause and Lubik (2006) specify a constant rate of separation to unemployment, and introduce permanent productivity differences across jobs to elicit OTJ search. Tasci (2006) posits that each match undergoes an initial phase of learning about productivity, the outcome of which may induce endogenous separation.

${ }^{3}$ These papers include Andolfatto (1996), Cooley and Quadrini (1999), Den Haan, Ramey and Watson (2000), Farmer and Hollenhorst (2006), Gertler and Trigari (2006), Hall (2006), Krause and Lubik (2007), Merz (1995), Rotemberg (2006) and Walsh (2003, 2005).
} 
combines the standard RBC model with a constant separation rate specification of the MP model to investigate the cyclical properties of unemployment and vacancies. In her simulated data, the standard deviations of unemployment and vacancies lie reasonably close to their empirical counterparts, suggesting that general equilibrium effects may have an important influence on the volatility of these variables.

The paper proceeds as follows. Section 2 introduces the four specifications of the MP model and constructs theoretical measures that correspond to the empirical data series. The calibration procedure and numerical solution method are discussed in Section 3, and results are presented in Section 4. In Section 5, the dynamic interrelationships of labor market variables are considered. Section 6 investigates the implications of the HagedornManovskii calibration approach, and Section 7 concludes.

\section{MP Model}

\section{$2.1 \quad$ Basics}

There is a unit mass of atomistic workers and an infinite mass of atomistic firms. Time periods are weekly. In any week $t$, a worker may be either matched with a firm or unemployed, while a firm may be matched with a worker, unmatched and posting a vacancy, or inactive.

Unemployed workers receive a flow benefit of $b$ per week, representing the total value of leisure, home production and unemployment insurance payments. Firms that post vacancies pay a posting cost of $c$ per week. Let $u_{t}$ and $v_{t}$ denote the number of unemployed workers and posted vacancies, respectively, in week $t$. The number of new matches formed in week $t$ is determined by a matching function $m\left(u_{t}, v_{t}\right)$, having a Cobb-Douglas form:

$$
m\left(u_{t}, v_{t}\right)=A u_{t}^{\alpha} v_{t}^{1-\alpha}
$$

Thus, an unemployed worker's probability of obtaining a match in week $t$ is $A \theta_{t}^{1-\alpha}$, where $\theta_{t}=v_{t} / u_{t}$ indicates market tightness. A vacancy obtains a match with probability $A \theta_{t}^{-\alpha}$. The value of $v_{t}$ in each week is determined by free entry.

A worker-firm match can produce an output level of $z_{t} x$ during week $t$, where $z_{t}$ and $x$ and are aggregate and match-specific productivity factors, respectively. The aggregate factor is determined according to the following process:

$$
\ln z_{t}=\rho_{z} \ln z_{t-1}+\varepsilon_{t}^{z}
$$


where $\varepsilon_{t}^{z}$ is an i.i.d. normal disturbance with mean zero and standard deviation $\sigma_{z}$ Determination of $x$ is discussed below.

Before engaging in production in week $t$, the worker and firm negotiate a contract that divides match surplus according to the Nash bargaining solution, where $\pi$ gives the worker's bargaining weight and the disagreement point is severance of the match. Let $S_{t}(x)$ indicate the value of match surplus in week $t$ for given $x$, and let $U_{t}$ and $V_{t}$ be the values received by an unemployed worker and a vacancy-posting firm, respectively. The worker and firm will agree to continue the match if $S_{t}(x)>0$, while they will separate if separation is jointly optimal, in which case $S_{t}(x)=0$. As the outcome of bargaining, the worker and firm receive payoffs of $\pi S_{t}(x)+U_{t}$ and $(1-\pi) S_{t}(x)+V_{t}$, respectively.

Let $x^{h}$ denote the value of the match-specific productivity in a new match. The unemployment and vacancy values satisfy

$$
\begin{gathered}
U_{t}=b+\beta E_{t}\left[A \theta_{t}^{1-\alpha} \pi S_{t+1}\left(x^{h}\right)+U_{t+1}\right], \\
V_{t}=-c+\beta E_{t}\left[A \theta_{t}^{-\alpha}(1-\pi) S_{t+1}\left(x^{h}\right)+V_{t+1}\right],
\end{gathered}
$$

where $\beta$ is the discount factor. In free entry equilibrium, $V_{t}=0$ holds for all $t$; thus, $\theta_{t}$ is determined by

$$
\beta A \theta_{t}^{-\alpha}(1-\pi) E_{t} S_{t+1}\left(x^{h}\right)=c
$$

\subsection{Exogenous separation}

In the exogenous separation version of the MP model, $x=x^{h}$ is assumed to hold at all times and for all matches. At the end of each week, matches face a risk of exogenous separation. Let $s_{t}$ denote the probability that any existing match separates at the end of week $t$. The exogenous separation probability is determined by

$$
\ln s_{t}=\rho_{s} \ln s_{t-1}+\left(1-\rho_{s}\right) \ln s+\varepsilon_{t}^{s},
$$

where $\varepsilon_{t}^{s}$ is i.i.d. normal with mean zero and standard deviation $\sigma_{s}$.

Let $M_{t}(x)$ denote the value of a match in week $t$ when the match-specific factor is $x$. Since the worker and firm seek to maximize match value as part of Nash bargaining, $M_{t}\left(x^{h}\right)$ must satisfy the following Bellman equation:

$$
M_{t}\left(x^{h}\right)=\max \left\{z_{t} x^{h}+\beta E_{t}\left[\left(1-s_{t}\right) M_{t+1}\left(x^{h}\right)+s_{t}\left(U_{t+1}+V_{t+1}\right)\right], U_{t}+V_{t}\right\} .
$$


Thus, match surplus may be expressed as

$$
\begin{aligned}
S_{t}\left(x^{h}\right) & =M_{t}\left(x^{h}\right)-U_{t}-V_{t} \\
& =\max \left\{z_{t} x^{h}+\beta E_{t}\left[\left(1-s_{t}\right) S_{t+1}\left(x^{h}\right)+U_{t+1}+V_{t+1}\right]-U_{t}-V_{t}, 0\right\} .
\end{aligned}
$$

Substituting for $U_{t}$ from (2) and setting $V_{t}=0$ for all $t$ yields

$$
S_{t}\left(x^{h}\right)=\max \left\{z_{t} x^{h}-b+\beta\left(1-s_{t}-A \theta_{t}^{1-\alpha} \pi\right) E_{t} S_{t+1}\left(x^{h}\right), 0\right\} .
$$

Equations (4) and (6) determine free entry equilibrium paths of $\theta_{t}$ and $S_{t}\left(x^{h}\right)$ for given realizations of the $z_{t}$ and $s_{t}$ processes.

\subsection{Endogenous separation}

In the endogenous separation version, $s_{t}$ is held constant at the value $s$, whereas $x$ follows a Markov process. All new matches start at $x=x^{h}$, but the value of $x$ may switch in subsequent weeks. At the end of each week $t$, a switch occurs with probability $\lambda$. In the latter event, the value of $x$ for week $t+1$ is drawn randomly according to the c.d.f. $G(x)$, taken to be lognormal with parameters $\mu_{x}$ and $\sigma_{x}$ for $x<x^{h}$, and $G\left(x^{h}\right)=1$. With probability $1-\lambda, x$ maintains its week $t$ value into week $t+1$.

When OTJ search is not allowed, match value satisfies

$$
\begin{aligned}
M_{t}(x)= & \max \left\{z_{t} x+\beta E_{t}\left[(1-s)\left\{\lambda \int_{0}^{x^{h}} M_{t+1}(u) d G(u)+(1-\lambda) M_{t+1}(x)\right\}\right.\right. \\
& \left.\left.+s\left(U_{t+1}+V_{t+1}\right)\right], U_{t}+V_{t}\right\} .
\end{aligned}
$$

Rearranging and substituting as above gives

$$
\begin{aligned}
S_{t}(x)= & \max \left\{z_{t} x-b+\beta(1-s)\left\{\lambda E_{t} \int_{0}^{x^{h}} S_{t+1}(u) d G(u)+(1-\lambda) E_{t} S_{t+1}(x)\right\}\right. \\
& \left.-\beta A \theta_{t}^{1-\alpha} \pi E_{t} S_{t+1}\left(x^{h}\right), 0\right\} .
\end{aligned}
$$

Equations (4) and (7) determine equilibrium paths of $\theta_{t}$ and $S_{t}(x)$ for given realizations of the $z_{t}$ process.

\subsection{OTJ search}

The OTJ search version of the MP model extends the endogenous separation version by allowing matched workers to search at a cost of $a$. The worker search pool expands to 
$u_{t}+\phi_{t}$, where $\phi_{t}$ indicates the number of matched workers who search in week $t$. Total match formation in week $t$ is now equal to $m\left(u_{t}+\phi_{t}, v_{t}\right)$. The matching probability for a searching worker, whether employed or unemployed, is $A \theta_{t}^{1-\alpha}$, and the probability that a vacancy contacts a worker is $A \theta_{t}^{-\alpha}$, where $\theta_{t}=v_{t} /\left(u_{t}+\phi_{t}\right)$.

When an OTJ searching worker makes a new match in week $t$, the worker must renounce the option of keeping his old match before bargaining with the new firm at the start of week $t+1$. As a consequence, the worker receives a payoff of $\pi S_{t+1}\left(x^{h}\right)+U_{t+1}$ from the new match. Since the worker's payoff from the old match cannot exceed this value, it is optimal for the worker always to accept a new match. Thus, when OTJ search is chosen, the match value is

$$
\begin{aligned}
M_{t}^{s}(x)= & z_{t} x-a+\beta E_{t}\left[A \theta_{t}^{1-\alpha}\left(\pi S_{t+1}\left(x^{h}\right)+U_{t+1}+V_{t+1}\right)\right. \\
& +\left(1-A \theta_{t}^{1-\alpha}\right)\left[(1-s)\left\{\lambda \int_{0}^{x^{h}} M_{t+1}(u) d G(u)+(1-\lambda) M_{t+1}(x)\right\}\right. \\
& \left.\left.+s\left(U_{t+1}+V_{t+1}\right)\right]\right]
\end{aligned}
$$

and the associated equilibrium match surplus is

$$
\begin{aligned}
S_{t}^{s}(x)= & z_{t} x-a-b+\beta\left(1-A \theta_{t}^{1-\alpha}\right)(1-s) \\
& \times\left\{\lambda E_{t} \int_{0}^{x^{h}} S_{t+1}(u) d G(u)+(1-\lambda) E_{t} S_{t+1}(x)\right\} .
\end{aligned}
$$

Assuming the worker's search decision is contractible, the Bellman equation for match surplus becomes

$$
\begin{aligned}
S_{t}(x)= & \max \left\{z_{t} x-a-b+\beta\left(1-A \theta_{t}^{1-\alpha}\right)(1-s)\right. \\
& \times\left\{\lambda E_{t} \int_{0}^{x^{h}} S_{t+1}(u) d G(u)+(1-\lambda) E_{t} S_{t+1}(x)\right\} \\
& z_{t} x-b+\beta(1-s)\left\{\lambda E_{t} \int_{0}^{x^{h}} S_{t+1}(u) d G(u)+(1-\lambda) E_{t} S_{t+1}(x)\right\} \\
& \left.-\beta A \theta_{t}^{1-\alpha} \pi E_{t} S_{t+1}\left(x^{h}\right), 0\right\} .
\end{aligned}
$$

Equilibrium $\theta_{t}$ and $S_{t}(x)$ are determined by (4) and (8) in this case.

\subsection{Measurement}

Equilibrium worker transition rates and flows are measured as follows. A worker who is unemployed in week $t$ becomes employed in week $t+1$ with probability $A \theta_{t}^{1-\alpha}$. Thus, the 
measured job finding rate and number of UE flows for week $t+1$ are

$$
J F R_{t+1}=A \theta_{t}^{1-\alpha}, \quad U E_{t+1}=A \theta_{t}^{1-\alpha} u_{t}
$$

Moreover, in the exogenous separation version, a worker who is employed in week $t$ becomes unemployed in week $t+1$ with probability $s_{t}$, giving the following measured separation rate and number of EU flows:

$$
S R_{t+1}=s_{t}, \quad E U_{t+1}=s_{t}\left(1-u_{t}\right)
$$

Separation rates and EU flows in the endogenous separation and OTJ search versions depend on the distribution of $x$ across existing matches. Let $e_{t}(x)$ denote the number of matches in week $t$ having match-specific factors less than or equal to $x$; note that $e_{t}\left(x^{h}\right)$ gives total employment. Since $S_{t}(x)$ is strictly increasing in $x$ wherever $S_{t}(x)>0$, there exists a value $R_{t}$ such that $S_{t}(x)=0$ if and only if $x \leq R_{t}$. Thus, separation occurs at the start of week $t+1$ whenever $x \leq R_{t+1} \cdot{ }^{4}$ In equilibrium, $e_{t+1}(x)=0$ for $x \leq R_{t+1}$, while for $x \in\left(R_{t+1}, x^{h}\right)$ :

$$
\begin{aligned}
e_{t+1}(x)= & (1-s) \lambda\left(G(x)-G\left(R_{t+1}\right)\right) e_{t}\left(x^{h}\right) \\
& +(1-s)(1-\lambda)\left(e_{t}(x)-e_{t}\left(R_{t+1}\right)\right) .
\end{aligned}
$$

Furthermore, for $x=x^{h}$ :

$$
\begin{aligned}
e_{t+1}\left(x^{h}\right)= & (1-s) \lambda\left(1-G\left(R_{t+1}\right)\right) e_{t}\left(x^{h}\right) \\
& +(1-s)(1-\lambda)\left(e_{t}\left(x^{h}\right)-e_{t}\left(R_{t+1}\right)\right)+A \theta_{t}^{1-\alpha} u_{t} .
\end{aligned}
$$

Total EU flows and the separation rate are given by

$$
\begin{gathered}
E U_{t+1}=\left(s+(1-s) \lambda G\left(R_{t+1}\right)\right) e_{t}\left(x^{h}\right)+(1-s)(1-\lambda) e_{t}\left(R_{t+1}\right), \\
S R_{t+1}=\frac{e u_{t+1}}{e_{t}\left(x^{h}\right)} .
\end{gathered}
$$

Finally, the implied law of motion for unemployment is

$$
u_{t+1}=u_{t}+E U_{t+1}-U E_{t+1} .
$$

\footnotetext{
${ }^{4}$ When $x=R_{t+1}$, the firm and worker could also choose to continue their match, as a matter of indifference. It is slightly more convenient for notational purposes to specify that separation occurs at the $R_{t+1}$ margin.
} 
In the exogenous and endogenous separation versions, vacancies are determined simply by

$$
v_{t}=\theta_{t} u_{t}
$$

In the OTJ search version, $\phi_{t}$ must be known in order to determine vacancies. It can be shown that there exists a value $R_{t}^{s}$ such that the match surplus from OTJ search exceeds the surplus from continuing the match with no search if and only if $x<R_{t}^{s}$. Thus, OTJ search is chosen whenever $x \in\left(R_{t}, R_{t}^{s}\right)$. It follows that $\phi_{t}=e_{t}\left(R_{t}^{s}\right)$ and

$$
v_{t}=\theta_{t}\left(u_{t}+e_{t}\left(R_{t}^{s}\right)\right)
$$

\section{Simulation}

\subsection{Calibration}

Two specifications of the exogenous separation version are considered: $s_{t}$ may either be constant at $s$, or else follow an $\operatorname{AR}(1)$ process given by (5) with $\sigma_{s}>0$. Combined with the endogenous separation and OTJ search versions, this gives four specifications to calibrate. Parameter choices for the four cases are given in columns two through four of Table 1 (columns five and six are discussed in Section 6).

The parameters $b, \alpha$ and $\pi$ are set to the standard values discussed by Mortensen and Nagypál (2007), and it suffices to let a equal zero in the OTJ search specification. Calibration of $c$ draws on survey evidence on employer recruitment behavior. Results cited in Barron, et al. (1997) point to an average vacancy duration of roughly three weeks. Moreover, Barron and Bishop's (1985) data show an average of about nine applicants for each vacancy filled, with two hours of work time required to process each application. These figures suggest an average investment of 20 hours per vacancy filled, or 6.7 hours per week the vacancy is posted. This amounts to 17 percent of a 40 hour work week; thus, it is reasonable to assign this value to $c$, given that weekly productivity is normalized to unity.

For the endogenous separation and OTJ search specifications, $\lambda$ is chosen to yield a mean waiting time of three months between switches of the match-specific productivity factor. To ensure comparability across specifications, $x^{h}$ is adjusted to generate mean match productivity of unity in all cases.

To select the parameters $\rho_{z}$ and $\sigma_{z}$, paths of $z_{t}$ are simulated using (1) and converted to monthly averages. $\rho_{z}$ and $\sigma_{z}$ are determined in order to match the productivity process 
estimated from the simulated data to the process used by Fujita and Ramey (2007). The latter process is based on monthly estimates that control for the possibility of endogenous feedbacks to productivity. The value of the weekly discount factor $\beta$ is consistent with an annual interest rate of four percent.

Selection of the remaining parameters relies on monthly job finding and separation rate data from Fujita and Ramey (2006). These data derive from the Current Population Survey for the 1976-2005 period, and are adjusted for margin error and time aggregation error. In all cases, the parameters $A$ and $s$ are chosen to ensure that the simulated data generate mean monthly job finding and separation rates of 34 percent and two percent, respectively, consistent with the Fujita-Ramey evidence.

In the $\operatorname{AR}(1)$ specification, $\rho_{s}$ and $\sigma_{s}$ are chosen to match the standard deviation and first-order autocorrelation of the simulated separation rate series, aggregated to quarterly and HP filtered (with smoothing parameter 1600), to the empirical values of these moments in the Fujita-Ramey data. This procedure is justified under the hypothesis that all variability in the separation rate is exogenous. Finally, the parameter $\mu_{x}$ is set to zero in the endogenous separation and OTJ search specifications, and $\sigma_{x}$ is adjusted to match the standard deviation of the simulated quarterly separation rate series, HP filtered, with its empirical value.

\subsection{Solution method}

The model consists of the free entry condition (4), the surplus equation (6), (7) or (8), and the driving processes (1) and (5). To solve the model, let the stochastic elements be represented on grids. The method of Tauchen (1986) is used to represent the processes $z_{t}$ and $s_{t}$ as Markov chains having state spaces $\left\{z_{1}, \ldots, z_{I}\right\}$ and $\left\{s_{1}, \ldots, s_{K}\right\}$ and transition matrices $\Delta^{z}=\left[\delta_{i j}^{z}\right]$ and $\Delta^{s}=\left[\delta_{k l}^{s}\right]$, where $\delta_{i j}^{z}=\operatorname{Prob}\left\{z_{t+1}=z_{j} \mid z_{t}=z_{i}\right\}$ and $\delta_{k l}^{s}=$ $\operatorname{Prob}\left\{s_{t+1}=s_{l} \mid s_{t}=s_{k}\right\} . G(x)$ is approximated by a discrete distribution with support $\left\{x_{1}, \ldots, x_{M}\right\}$, satisfying $x_{1}=1 / M, x_{m}-x_{m-1}=x^{h} / M$ and $x_{M}=x^{h}$. The associated probabilities $\left\{\gamma_{1}, \ldots, \gamma_{M}\right\}$ are $\gamma_{m}=g\left(x_{m}\right) / M$ for $m=1, \ldots, M-1$, where $g(x)$ is the lognormal density, and $\gamma_{M}=1-\gamma_{1}-\ldots-\gamma_{M-1}$.

Market tightness and match surplus may be represented as

$$
\theta_{t}=\theta\left(z_{i}, s_{k}\right), \quad S_{t}\left(x_{m}\right)=S\left(z_{i}, s_{k}, x_{m}\right)
$$

where $z_{i}$ and $s_{k}$ are the states prevailing in period $t$. Equations (4), (6) and (7) take the 
forms, for $i=1, \ldots, I, k=1, \ldots, K, m=1, \ldots, M$ :

$$
\begin{aligned}
& \beta A \theta\left(z_{i}, s_{k}\right)^{-\alpha}(1-\pi) \sum_{j, l} \delta_{i j}^{z} \delta_{k l}^{s} S\left(z_{j}, s_{l}, x^{h}\right)=c, \\
& S\left(z_{i}, s_{k}, x^{h}\right)=\max \left\{z_{i} x^{h}-b\right. \\
& \left.+\beta\left(1-s_{k}-\beta A \theta\left(z_{i}, s_{k}\right)^{1-\alpha} \pi\right) \sum_{j, l} \delta_{i j}^{z} \delta_{k l}^{s} S\left(z_{j}, s_{l}, x^{h}\right), 0\right\}, \\
& S\left(z_{i}, s_{k}, x_{m}\right)=\max \left\{z_{i} x_{m}-b+\beta\left(1-s_{k}\right) \lambda \sum_{j, l, n} \delta_{i j}^{z} \delta_{k l}^{s} \gamma_{n} S\left(z_{j}, s_{l}, x_{n}\right)\right. \\
& +\beta\left(1-s_{k}\right)(1-\lambda) \sum_{j, l} \delta_{i j}^{z} \delta_{k l}^{s} S\left(z_{j}, s_{l}, x_{m}\right) \\
& \left.-\beta A \theta\left(z_{i}, s_{k}\right)^{1-\alpha} \pi \sum_{j, l} \delta_{i j}^{z} \delta_{k l}^{s} S\left(z_{j}, s_{l}, x^{h}\right), 0\right\}
\end{aligned}
$$

and similarly for (8).

Numerical solutions are obtained via backward substitution. For example, let $\theta^{T}\left(z_{i}, s_{k}\right)$ and $S^{T}\left(z_{i}, s_{k}, x^{h}\right)$ be the functions obtained after $T$ iterations of (9) and (10). At iteration $T+1$, these functions are updated to

$$
\begin{aligned}
& S^{T+1}\left(z_{i}, s_{k}, x^{h}\right)= \max \left\{z_{i} x^{h}-b\right. \\
&+\beta\left(1-s_{k}-\beta A \theta^{T}\left(z_{i}, s_{k}\right)^{1-\alpha} \pi\right) \sum_{j, l} \delta_{i j}^{z} \delta_{k l}^{s} S^{T}\left(z_{j}, s_{l}, x^{h}\right), \\
& \theta^{T+1}\left(z_{i}, s_{k}\right)=\left(\frac{\beta A(1-\pi)}{c} \sum_{j, l} \delta_{i j}^{z} \delta_{k l}^{s} S^{T+1}\left(z_{j}, s_{l}, x^{h}\right)\right)^{\frac{1}{\alpha}} .
\end{aligned}
$$

Convergence follows as a consequence of the saddlepoint stability property of the matching model, which makes for stability in the backward dynamics. ${ }^{5}$

\subsection{Evaluation procedure}

The empirical data series used for purposes of model evaluation are constructed as follows. Employment, unemployment, job finding and separation rates, and UE and EU flows are quarterly averages of the monthly series from Fujita and Ramey (2006), covering 1976Q22005Q4. The productivity series is obtained by dividing quarterly GDP by the employment

\footnotetext{
${ }^{5}$ In solving the model, $I=K=13$ and $M=200$ are chosen. The tolerance for pointwise convergence of $\theta\left(z_{i}, s_{k}\right)$ and $S\left(z_{i}, s_{k}, x_{m}\right)$ is $10^{-8}$.
} 
series. Vacancies are measured as quarterly averages of the Conference Board's monthly Help Wanted Index. All quarterly series are logged and HP filtered, with a smoothing parameter of 1600 .

To conform with the empirical series, the simulated weekly data are averaged to quarterly frequency, logged and HP filtered using the same smoothing parameter. Each simulated quarterly series consists of 619 observations, of which the last 119 are used to calculate the reported statistics. For each of the four specifications, 1000 replications are run, and averages of the statistics across the replications are presented in the figures.

\section{Results}

\subsection{Unemployment and worker transition rates}

Panel A of Figure 1 compares the empirical standard deviations of unemployment and worker transition rates with the values obtained from the four specifications of the MP model. The empirical standard deviation of unemployment, equalling 9.5 percent, is over eight times greater than the value of roughly 1.2 percent generated by the constant separation rate specification. This conforms to the observation of Costain and Reiter (2006) and Shimer (2005) that the MP model with a constant separation rate produces far too little unemployment volatility.

However, the empirical separation rate is not in fact constant, as it has a standard deviation of 5.8 percent. The other three versions of the MP model, which allow for fluctuations in the separation rate, are calibrated to match the latter standard deviation. All three specifications yield significantly greater unemployment volatility. The standard deviation of unemployment in the OTJ search specification, in particular, is 5.8 percent, or over 60 percent of its empirical value. Thus, incorporating variability at the separation margin, under any of the three specifications, greatly enhances the ability of the MP model to produce realistic unemployment volatility.

At the same time, all four specifications of the MP model yield highly unrealistic volatility of the job finding rate, with the empirical standard deviation being nearly six times the simulated value in each specification. Improving the model's performance at the separation margin does not mitigate its problems at the job finding margin.

Panel B of Figure 1 presents contemporaneous correlations with productivity. The constant, endogenous and OTJ search specifications each produce strong negative comove- 
ment between unemployment and productivity, in line with the data, while the $\operatorname{AR}(1)$ specification generates little comovement. All four specifications give rise to strong positive productivity comovement for the job finding rate. The two exogenous separation specifications, however, fail to replicate the negative correlation between productivity and the separation rate that is observed in the data. The two endogenous separation rate specifications succeed in capturing this negative correlation.

Elasticities of the variables with respect to productivity are shown in Panel C. ${ }^{6}$ The productivity elasticities offer more concrete measures of comovement, insofar as they capture the effects of variations in productivity in isolation from other disturbances; see Mortensen and Nagypál (2007). The elasticities may also be interpreted as rough measures of responsiveness to productivity shocks. For unemployment, the empirical productivity elasticity of -6.5 is over six times greater in magnitude than the elasticities produced by the two exogenous separation specifications. However, each of the endogenous separation specifications achieves a close match with the empirical elasticity; the value for the OTJ search model, in particular, comes in at -6.3 .

Findings are similar for the separation rate elasticities, where the exogenous separation specifications provide highly unrealistic values, while those of the endogenous separation specifications are empirically reasonable. Across all four specifications, however, the productivity elasticities of the job finding rate are far too low: the empirical value is 4.0, while the simulated values do not exceed 1.4.

In summary, introducing variability at the separation margin greatly magnifies the degree of unemployment volatility generated by the MP model, whether the separation rate is determined exogenously or endogenously. Moreover, when the separation rate is endogenous, the model generates realistic responsiveness of unemployment and the separation rate to productivity shocks, whereas the exogenous separation versions yield little or no responsiveness. For all of the specifications considered, the simulated job finding rate is deficient in both its volatility and its responsiveness to productivity.

\subsection{Worker flows}

Figure 2 considers gross flows of workers between unemployment and employment. As Panel A indicates, the constant separation rate specification produces almost no volatility

\footnotetext{
${ }^{6}$ These productivity elasticities are computed as follows. Let $p_{t}$ denote productivity in quarter $t$, and let $y_{t}$ be any series. Then the productivity elasticitiy is $\operatorname{Corr}\left(p_{t}, y_{t}\right) S D\left(y_{t}\right) / S D\left(p_{t}\right)$.
} 
in UE and EU flows. This is contrary to the data, where the standard deviations for both flows are roughly half of the value for unemployment. The three specifications with variable separation rates, in contrast, do a good job in matching the empirical standard deviations of both UE and EU flows. Thus, variability at the separation margin appears to be crucial for producing realistic variability in worker flows.

Panel B shows that with constant separation rates, worker flows exhibit a strong positive correlation with productivity. This contradicts the substantial negative correlation seen in the data. In the constant separation rate model, worker flows are driven principally by procyclical movements in the job finding rate, allowing little scope for explaining their observed countercyclical movements. The AR(1) model, in turn, yields essentially acyclical movements in worker flows, reflecting the fact that exogenous separation rate shocks are uncorrelated with the productivity process.

The two endogenous separation rate specifications, on the other hand, produce strong negative correlations between productivity and worker flows. Overall, as Panel $\mathrm{C}$ reveals, worker flows are almost entirely unresponsive to productivity in the two exogenous separation rate specifications, whereas they exhibit strong negative responses in the two endogenous separation specifications.

\subsection{Vacancies and market tightness}

Vacancies and market tightness are considered in Figure 3. Panel A shows that all four specifications imply insufficient volatility of both vacancies and market tightness, consistent with the low volatility of the job finding rate observed in Figure 1. The standard deviation of market tightness in the OTJ search model is somewhat greater than in the other specifications, however. This occurs because empirical market tightness is measured as vacancies divided by unemployment, whereas the variable $\theta_{t}$ also includes employed searching workers in its denominator. Thus, the empirical measure omits procyclical movements in the number of employed searchers that offset countercyclical movements in unemployment, leading to greater variability of the measured ratio.

Panel B depicts the productivity correlations. Both versions of the exogenous separation model replicate the procyclical movements of vacancies seen in the data, whereas the endogenous separation model without OTJ search yields countercyclical movements. The latter finding reflects conflicting effects on the incentive to post vacancies. Following a negative productivity shock, the returns to forming a new match are relatively low, re- 
ducing vacancy posting incentives. This effect drives vacancies downward in the constant and AR(1) models. In the endogenous separation model without OTJ search, however, the separation rate rises in response to the productivity shock, pushing up the number of unemployed workers. This increases the vacancy matching probability and enhances the incentive to post vacancies. On balance, the latter effect dominates, and vacancies become negatively correlated with productivity.

The OTJ search model, however, produces a strong positive correlation between vacancies and productivity, despite the fact that the separation rate is determined endogenously. With OTJ search, a negative productivity shock induces a fall in the number of employed searchers which partially offsets the rise in unemployment. Thus, endogenous separation is consistent with realistic vacancy comovement once OTJ search is incorporated. Note finally that all four specifications yield positive productivity comovement for market tightness, in line with the data.

Productivity elasticities are shown in Panel C. The empirical productivity elasticity of vacancies is roughly three times greater than the value for the OTJ search model, and the difference is even larger for the other three specifications. For market tightness, the OTJ search model performs better, as the simulated productivity elasticity amounts to 60 percent of the empirical value. Thus, while variability and productivity responsiveness are insufficient for all four specifications of the MP model, the OTJ search version improves on the others.

\subsection{Beveridge correlation}

Panel A of Figure 4 presents contemporaneous correlations between unemployment and vacancies, capturing the Beveridge curve relationship. The value of -0.95 observed in the data is reasonably well matched by the value -0.76 generated by the constant separation rate specification. The $\mathrm{AR}(1)$ specification, in contrast, produces a highly counterfactual value of 0.75 , and for the endogenous separation specification the value is an even more unrealistic 0.92 . In the $\mathrm{AR}(1)$ model, a small positive separation rate shock induces a large inflow into unemployment, because the stock of employed workers is relatively large. Workers become easier to find, while productivity is unchanged, so incentives to post vacancies rise. A related effect operates in the endogenous separation model, where a negative productivity shock drives up unemployment, making workers easier to find and raising the incentive to post vacancies. 
For the OTJ search model, the unemployment-vacancy correlation amounts to -0.96 , nearly indistinguishable from the empirical value. Here, procyclical movements in the number of employed searchers lead to procyclical changes in vacancy posting incentives, giving rise to a realistic Beveridge correlation.

\subsection{Transition rate comovement}

Contemporaneous correlations between job finding and separation rates are depicted in panel $\mathrm{B}$ of Figure 4. In the data, these rates have a negative correlation of about -0.5 , whereas the correlations are essentially zero in the two exogenous separation specifications. The two endogenous separation specifications, on the other hand, produce strong negative correlations, on the order of -0.88 . The latter specifications achieve the correct transition rate comovement chiefly because the two rates themselves respond realistically to the common underlying productivity process.

\section{Dynamic interrelationships}

\subsection{Cross productivity elasticities}

Figures 5 through 7 present elasticities with productivity at various leads and lags. To clarify the discussion, only the constant and OTJ search specifications are considered; findings are qualitatively similar for the other specifications.

Panel A of Figure 5 shows the elasticities of unemployment with respect to productivity at each of the given lags; e.g., the reported elasticity at a lag of 1 represents the correlation between current unemployment and productivity lagged by one quarter, multiplied and divided by the appropriate standard deviations. Empirically, the responsiveness of unemployment to productivity achieves its peak of -8 at a lag of two quarters. For the OTJ search model, the peak of just under -6 is reached at a $0-1$ quarter lag. Thus, the model fails to produce realistic response dynamics, in that responses occur more quickly than in the data. A similar finding can be observed for the constant separation rate model.

Cross productivity elasticities for the job finding rate are given in panel $\mathrm{B}$. The empirical job finding rate responds more slowly than does unemployment, with the peak elasticity occurring at a lag of three quarters. For both specifications of the MP model, in contrast, the elasticities peak sharply at zero lag. Thus, while the actual productivity responses of the job finding rate are spread out across time, they occur more or less contemporaneously 
with productivity in the MP model. Cross elasticities for vacancies and market tightness, shown in Figure 7, display similar properties. As stressed by Fujita and Ramey (2007), the fact that vacancies can jump instantaneously in the MP model causes market tightness to respond too quickly to productivity shocks. This undermines the model's ability to generate realistic dynamic responses of unemployment, the job finding rate, vacancies and market tightness.

Panel $\mathrm{C}$ of Figure 5 depicts the cross elasticities for the separation rate, while the cross elasticities for UE and EU flows are given in Figure 6. In these instances, the OTJ search model does a reasonable job of matching the empirical response pattern: the separation rate and EU flows adjust contemporaneously with productivity or lead it slightly, while UE flows lag productivity by about a quarter. In the constant separation rate model, in contrast, these variables are essentially unresponsive to productivity at all leads and lags.

In summary, the MP model with endogenous separation yields sensible dynamics of the separation rate and worker flows, whereas the responses of unemployment, the job finding rate, vacancies and market tightness are insufficiently sluggish. In no case does the model with exogenous separation deliver a realistic pattern of responses.

\subsection{Beveridge correlations}

Cross correlations between unemployment and vacancies are given in panel A of Figure 8. While both the constant and OTJ search specifications provide strong negative Beveridge correlations, in the constant separation rate model the peak correlation is achieved at a lead of one quarter, i.e., vacancies lead unemployment by one quarter, whereas in the data the peak occurs at zero lag. This reflects the mechanics of the model, wherein changes in unemployment are driven by changes in the job finding rate, which themselves are tied to fluctuations in vacancies. The OTJ search model, on the other hand, exhibits its peak correlation at zero lag, and matches fairly well the dynamic pattern seen in the data.

\subsection{Transition rate correlations}

Panel B of Figure 8 reports the cross correlations of job finding and separation rates. In the data, strong negative correlations are achieved at lags of -1 to -4 quarters, meaning that the separation rate leads the job finding rate. While the correlations for the OTJ search model exhibit a slight negative phase shift, they fail to capture adequately the overall dynamic pattern. Of course, all of these correlations are zero in the constant separation 
rate model.

\section{Hagedorn-Manovskii calibration}

Hagedorn and Manovskii (forthcoming, henceforth HM) propose an alternative approach to calibrating the MP model that draws on wage and profit data. In all four specifications of the MP model, the wage rate determined by Nash bargaining is

$$
w_{t}(x)=(1-\pi) b+\pi\left(z_{t} x+\theta_{t} c\right)
$$

where $x$ is identically equal to $x^{h}$ in the exogenous separation specifications. HM point out that under standard calibrations, the empirical productivity elasticity of wages is much lower than the elasticity generated by the model. They propose an alternative calibration strategy that aims to match this elasticity, along with the empirical relationship between mean wage and profit levels.

To assess the implications of the HM calibration, this paper follows Hornstein, et al. (2005) in varying the calibrated values of $b$ and $\pi$ in order to set the productivity elasticity of wages and the steady state wage-productivity ratio to the values 0.5 and 0.97 , respectively. For brevity, only the constant and OTJ search specifications are considered.

The new calibrations are reported in columns five and six of Table 1. As noted by Hornstein, et al., matching the empirical statistics requires large increases in the $b$ parameter and large decreases in the $\pi$ parameter. For the constant separation rate model, the $A$ parameter is adjusted to match the mean job finding rate, while for the OTJ search model the parameters $x^{h}, s$ and $\sigma_{x}$ are also adjusted to normalize mean productivity and match the mean and standard deviation of the separation rate. The model is solved and simulated according to the procedures discussed earlier.

Results are presented in Figures 9 through 12, which parallel Figures 1 through 4 in their content. Statistics pertaining to the standard calibrations of the constant and OTJ search specifications, taken from the earlier figures, are depicted alongside statistics obtained from the corresponding HM calibrations. Panel A of Figure 9 demonstrates that the HM calibration produces much more realistic volatility of unemployment and the job finding rate for both specifications. Moreover, the job finding rate becomes highly responsive to productivity, as seen in panel C. The responsiveness of the separation rate in the OTJ search model declines considerably, however. This reflects the fact that, following 
a negative productivity shock, strong downward movement in the job finding rate reduces separation incentives by degrading workers' outside option.

Figure 10 reveals that the HM calibration enhances the volatility of UE flows in the constant separation rate model, but it does not appreciably raise the volatility of EU flows, nor does it mitigate the counterfactual procyclicality of worker flows implied by this specification. Moreover, worker flows become less responsive to productivity in the OTJ search model. For UE flows, in particular, strong procyclical movements in the job finding rate serve to neutralize the countercyclical movements in the separation rate, leaving virtually no responsiveness to productivity.

The HM calibration greatly improves the performance of both specifications in matching the empirical features of vacancies and market tightness, as Figure 11 demonstrates. Finally, the Beveridge and transition rate correlations are presented in Figure 12. These are essentially unaffected for the constant separation rate model, while they become somewhat smaller in magnitude for the OTJ search model. Under the HM calibration, matching the empirical standard deviation of the separation rate necessitates a smaller role for fluctuations at the OTJ search margin, so that procyclical adjustments in the number of employed searchers do not work as strongly to offset countercyclical unemployment movements. The Beveridge correlation nonetheless remains substantially negative.

\section{Conclusion}

This paper considers four specifications of the standard MP model that differ in how they treat the separation margin. The specifications are calibrated at weekly frequency and solved using a nonlinear method. Allowing for realistic time variation of the separation rate greatly increases the volatility of unemployment in the simulated data. In the specification with OTJ search, for example, the standard deviation of unemployment equals 60 percent of its empirical value. Thus, moving beyond constant separation rates goes a long way towards redressing the problem of insufficient unemployment volatility in the MP model.

Both of the specifications with exogenous separation rates fail to reproduce the empirical volatility and productivity comovement of the separation rate and worker flows. The endogenous separation specifications, in contrast, yield empirically reasonable behavior along these dimensions, and the specification with OTJ search also generates a realistic Beveridge curve correlation. Furthermore, the endogenous separation specifications imply more realistic dynamic interrelationships in comparison to the exogenous separation ones. 
Two broad conclusions emerge from this analysis. First, the endogenous separation specification with OTJ search dominates both of the exogenous separation specifications along all dimensions considered. From the empirical standpoint, there seems to be no justification for assuming exogenous separation when modelling the separation margin.

Second, the OTJ search version of the MP model, as articulated in Pissarides (2000), does a remarkable job in matching labor market facts even under the standard calibration, although the model still generates insufficient volatility of the job finding rate and related variables. Adopting the HM calibration addresses the latter failings, and only two deficiencies remain: UE flows do not exhibit realistic productivity comovement; and the dynamic responsiveness of key variables remains insufficiently sluggish.

The HM calibration approach might not, however, constitute a final resolution to the volatility deficiencies of the MP model, to the extent that it relies on values of the unemployment benefit parameter that may be unrealistically high. Introducing forms of wage rigidity, as advocated by Hall (2005), may prove a more successful path. In any event, the present paper shows that handling the separation margin in a realistic manner does not by itself entirely resolve the "volatility puzzle."

Finally, the inability of the MP model to generate sluggish dynamics suggests that it does not deal adequately with key structural features of the labor market. Fujita and Ramey (2007) argue that fixed costs of vacancy creation may be salient in practice, and they show that introducing these costs into the MP model with constant separation rates leads to substantial improvements in its dynamic performance. Further investigations in this direction might lead to a more complete resolution of this "propagation puzzle." 


\section{References}

Andolfatto, David. "Business Cycles and labor-Market Search." American Economic Review, March 1996, 86(1), pp. 112-32.

Barron, John M., Berger, Mark C., and Black, Dan A. "Employer Search, Training, and Vacancy Duration." Economic Inquiry, January 1997, 35(1), 167-92.

Barron, John M., and Bishop, John. "Extensive Search, Intensive Search, and Hiring Costs: New Evidence on Employer Hiring Activity." Economic Inquiry, July 1985, 23(3), $363-82$.

Cooley, Thomas F., and Quadrini, Vincenzo. "A Neoclassical Model of the Phillips Curve Relationship." Journal of Monetary Economics, October 1999, 44(2), 165-93.

Costain, James S., and Reiter, Michael. "Business Cycles, Unemployment Insurance, and the Calibration of Matching Models." Draft, Bank of Spain and Universitat Pompeu Fabra, October 2006.

Cole, Harold L., and Rogerson, Richard. "Can the Mortensen-Pissarides Matching Model Match the Business Cycle Facts?" International Economic Review, November 1999, 40(4), 933-59.

Den Haan, Wouter J., Ramey, Garey, and Watson, Joel. "Job Destruction and Propagation of Shocks." American Economic Review, June 2000, 90(3), pp. 482-98.

Farmer, Roger E.A., and Hollenhorst, Andrew. "Shooting the Auctioneer." Draft, UCLA, August 2006.

Fujita, Shigeru. "The Beveridge Curve, Job Creation, and the Propagation of Shocks." Draft, UCSD, 2003.

Fujita, Shigeru. "Vacancy Persistence." Working Paper No, 04-23, Federal Reserve Bank of Philadelphia, October 20, 2004.

Fujita, Shigeru and Ramey, Garey. "The Cyclicality of Job Loss and Hiring." Federal Reserve Bank of Philadelphia Working Paper 06-17, November 2006. 
Fujita, Shigeru and Ramey, Garey. "Job Matching and Propagation." Journal of Economic Dynamics and Control, November 2007, 31(11), pp. 3671-98.

Gertler, Mark, and Trigari, Antonella. "Unemployment Fluctuations with Staggered Nash Wage Bargaining." Draft, NYU and Università Bocconi, July 2006.

Hagedorn, Marcus, and Manovskii, Iourii. "The Cyclical Behavior of Equilibrium Unemployment and Vacancies Revisited." American Economic Review, forthcoming.

Hall, Robert E. "Employment Fluctuations with Equilibrium Wage Stickiness." American Economic Review, March 2005, 95(1), pp. 50-65.

Hall, Robert E. "The Labor Market and Macro Volatility: A Nonstationary General Equilibrium Analysis.” Draft, Stanford University, April 9, 2006.

Hornstein, Andreas, Krusell, Per, and Violante, Giovanni L. "Unemployment and Vacancy Fluctuations in the Matching Model: Inspecting the Mechanism." Federal Reserve Bank of Richmond Economic Quarterly, Summer 2005, 91(3), pp. 19-51.

Krause, Michael U. and Lubik, Thomas A. "The Cyclical Upgrading of Labor and Onthe-Job Search." Labour Economics, August 2006, 13(4), pp. 459-77.

Krause, Michael U. and Lubik, Thomas A. "The (Ir)relevance of Real Wage Rigidity in the New Keynesian Model with Search Frictions." Journal of Monetary Economics, April 2007, 54(3), pp. 706-27.

Merz, Monika. "Search in the Labor Market and the Real Business Cycle." Journal of Monetary Economics, November 1995, 36(2), pp. 269-300.

Mortensen, Dale T. "The Cyclical Behavior of Job and Worker Flows." Journal of Economic Dynamics and Control, November 1994, 18(6), pp. 1121-42.

Mortensen, Dale T. "More on Unemployment and Vacancy Fluctuations." Discussion Paper No. 1765, IZA, September 2005.

Mortensen, Dale T., and Nagypál, Éva. "More on Unemployment and Vacancy Fluctuations." Review of Economic Dynamics, July 2007, 10(3), pp. 327-47. 
Mortensen, Dale T. and Pissarides, Christopher A. "Job Creation and Job Destruction in the Theory of Unemployment." Review of Economic Studies, July 1994, 61(3), pp. $397-415$.

Nagypál, Éva. "On the Extent of Job-to-Job Transitions." Draft, Northwestern University, September 2005a.

Nagypál, Éva. "Labor-Market Fluctuations, On-the-Job Search, and the Acceptance Curse." Draft, Northwestern University, December 6, 2005b.

Pissarides, Christopher A. "Search Unemployment with On-the-Job Search." Review of Economic Studies, July 1994, 61(3), pp. 457-75.

Pissarides, Christopher A. Equilibrium Unemployment Theory. Cambridge, MA: MIT Press, 2000.

Pissarides, Christopher A.. "The Unemployment Volatility Puzzle: Is Wage Stickiness the Answer?" Draft, LSE, June 22, 2007.

Rotemberg, Julio. "Cyclical Wages in a Search-and-Bargaining Model with Large Firms." Draft, Harvard Business School, February 27, 2006.

Shimer, Robert. "The Cyclical Behavior of Equilibrium Unemployment and Vacancies." American Economic Review, March 2005, 95(1), pp. 25-49.

Tasci, Murat. "On-the-Job Search and Labor Market Reallocation." Draft, University of Texas at Austin, February 13, 2006.

Tauchen, George. "Finite State Markov-Chain Approximations to Univariate and Vector Autoregressions." Economics Letters, 1986, 20(2), pp. 177-81.

Walsh, Carl E. "Labor Market Search and Monetary Shocks." In Altug, Sumru, Chandha, Jagjit S., and Nolan, Charles, eds. Dynamic Macroeconomic Analysis: Theory and Policy in General Equilibrium. Cambridge: Cambridge University Press, 2003.

Walsh, Carl E. "Labor Market Search, Sticky Wages, and Interest Rate Policies." Review of Economic Dynamics, October 2005, 8(4), pp. 829-849.

Yashiv, Eran. "Evaluating the Performance of the Search and Matching Model." European Economic Review, May 2006a, 50(4), pp. 909-36. 


\section{Table 1 Parameter values}

\begin{tabular}{|c|c|c|c|c|c|c|}
\hline Parameter & Constant & $\underline{A R(1)}$ & Endog & OTJ search & Constant-HM & OTJ Search-HM \\
\hline$b$ & 0.7 & 0.7 & 0.7 & 0.7 & 0.955 & 0.934 \\
\hline C & 0.17 & 0.17 & 0.17 & 0.17 & 0.17 & 0.17 \\
\hline$a$ & - & - & - & 0 & - & 0 \\
\hline$A$ & 0.083 & 0.083 & 0.081 & 0.077 & 0.068 & 0.056 \\
\hline$\alpha$ & 0.6 & 0.6 & 0.6 & 0.6 & 0.6 & 0.6 \\
\hline$\pi$ & 0.6 & 0.6 & 0.6 & 0.6 & 0.07 & 0.062 \\
\hline$x^{h}$ & 1.00 & 1.00 & 1.17 & 1.28 & 1.00 & 1.13 \\
\hline$s$ & 0.005 & 0.005 & 0.0015 & 0.003 & 0.005 & 0.0048 \\
\hline$\rho_{s}$ & 0 & 0.97 & - & - & - & - \\
\hline$\sigma_{s}$ & 0 & 0.0168 & - & - & - & - \\
\hline$\lambda$ & - & - & 0.085 & 0.085 & - & 0.085 \\
\hline$\mu_{x}$ & - & - & 0 & 0 & - & 0 \\
\hline$\sigma_{x}$ & - & - & 0.2275 & 0.4510 & - & 0.1426 \\
\hline$\rho_{z}$ & 0.99 & 0.99 & 0.99 & 0.99 & 0.99 & 0.99 \\
\hline$\sigma_{z}$ & 0.0027 & 0.0027 & 0.0027 & 0.0027 & 0.0027 & 0.0027 \\
\hline$\beta$ & 0.9992 & 0.9992 & 0.9992 & 0.9992 & 0.9992 & 0.9992 \\
\hline
\end{tabular}

Notes: $b$ : unemployment payoff. $c$ : vacancy posting cost. $a$ : OTJ search cost. $A, \alpha$ : parameters of matching function. $\pi$ : worker bargaining weight. $x^{h}$ : highest value of match-specific productivity factor. $s$ : mean exogenous separation probability. $\rho_{s}, \sigma_{s}$ : parameters of exogenous separation process. $\lambda, \mu_{x}, \sigma_{x}$ : parameters of match-specific productivity process. $\rho_{z}, \sigma_{z}$ : parameters of aggregate productivity process. $\beta$ : discount factor. See text for explanation of calibration procedure. 
Figure 1. Unemployment and worker transition rates

\section{A. Standard deviations}

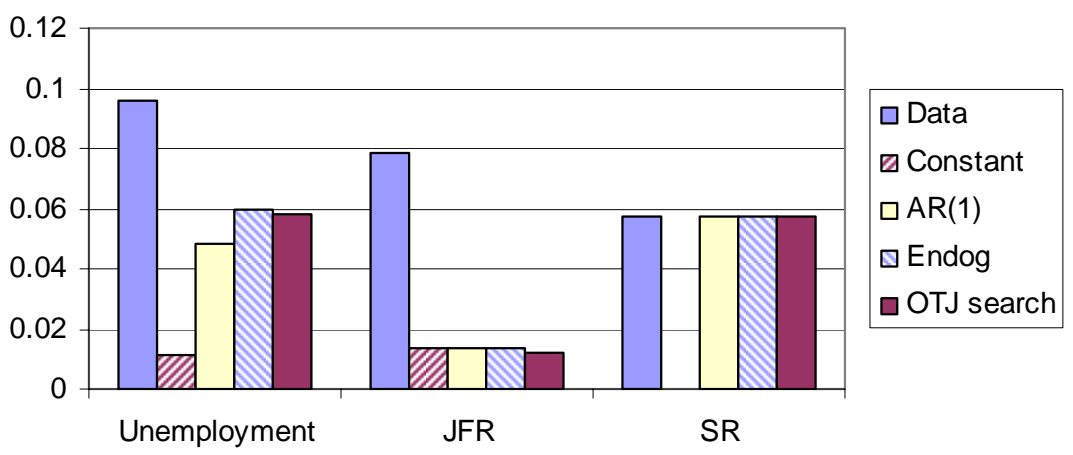

B. Productivity correlations

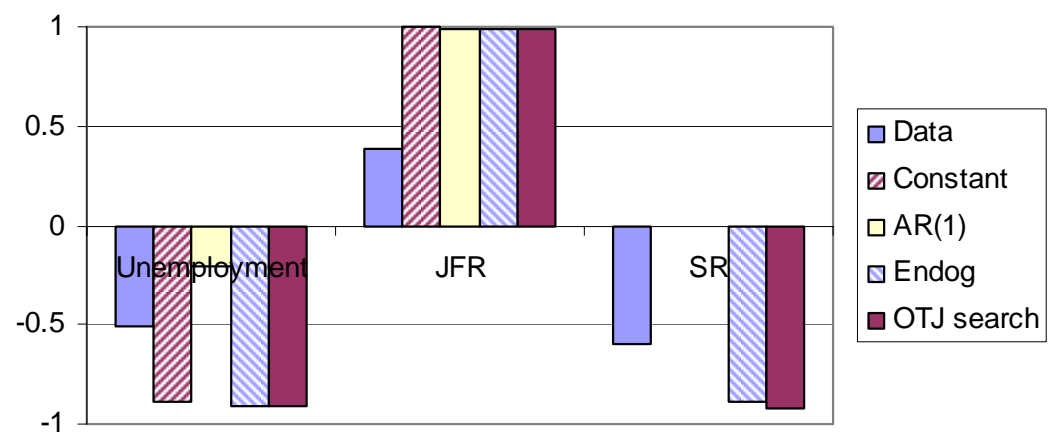

\section{Productivity elasticities}

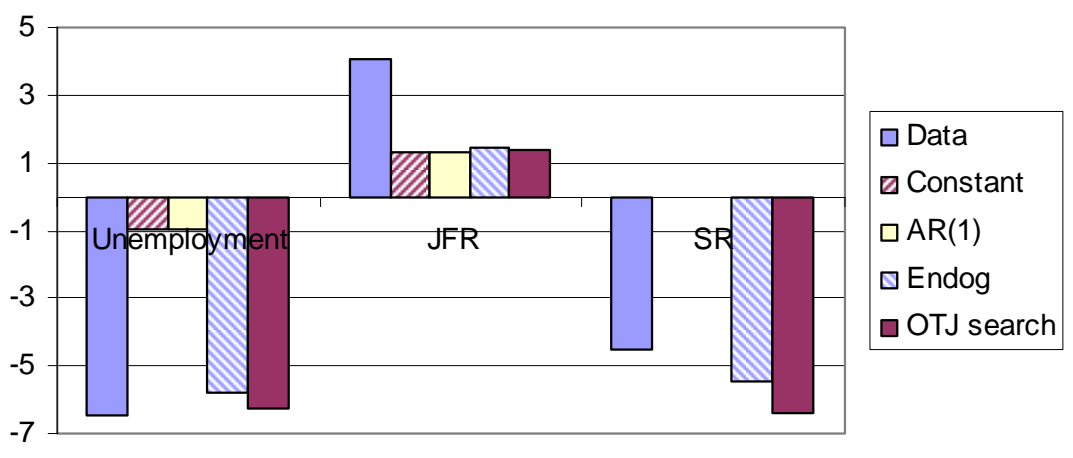


Figure 2. Worker flows

A. Standard deviations

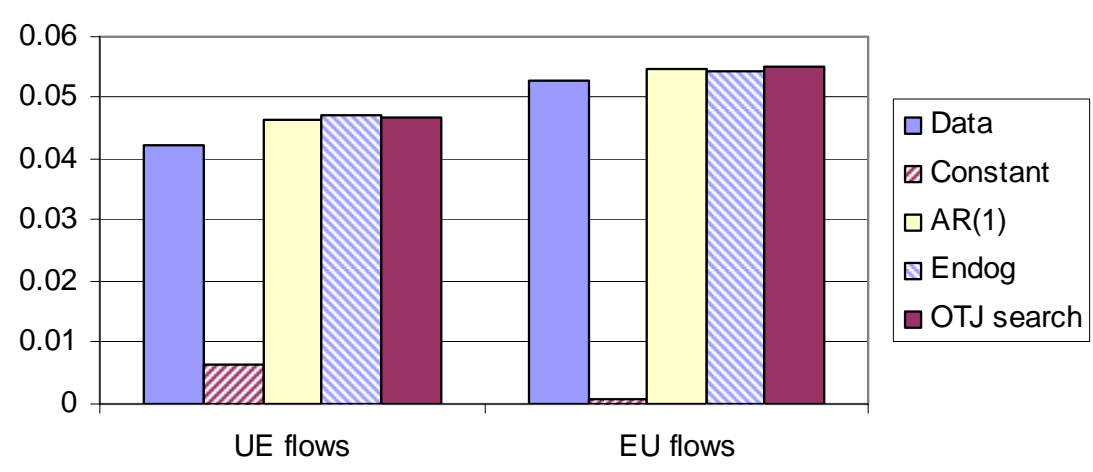

B. Productivity correlations

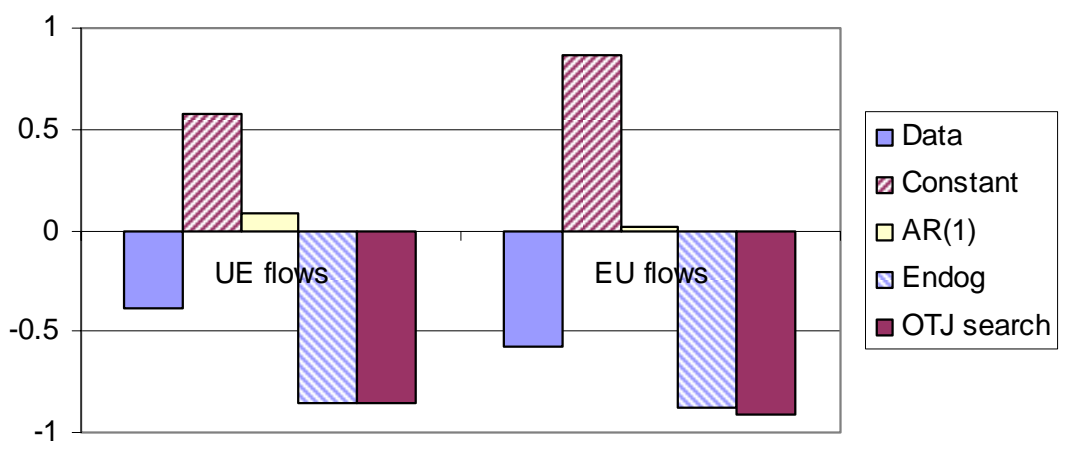

C. Productivity elasticities

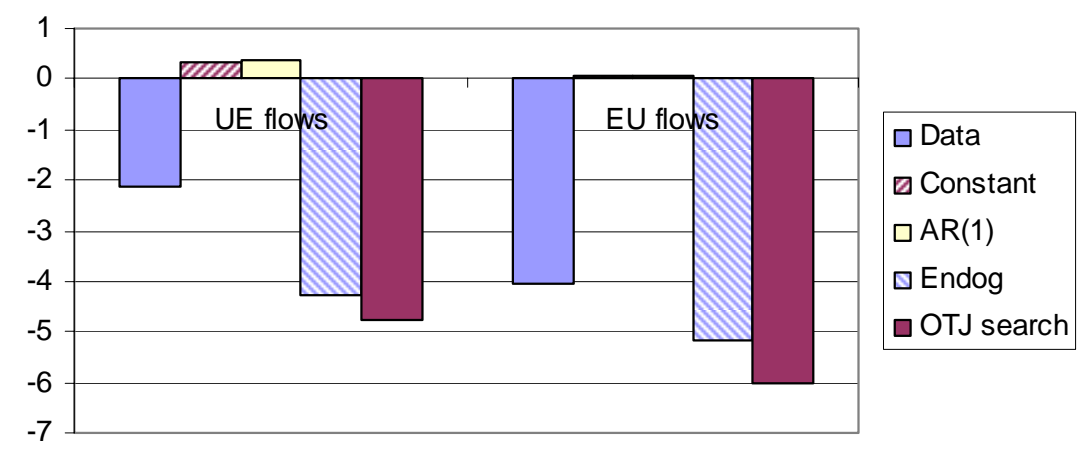


Figure 3. Vacancies and market tightness

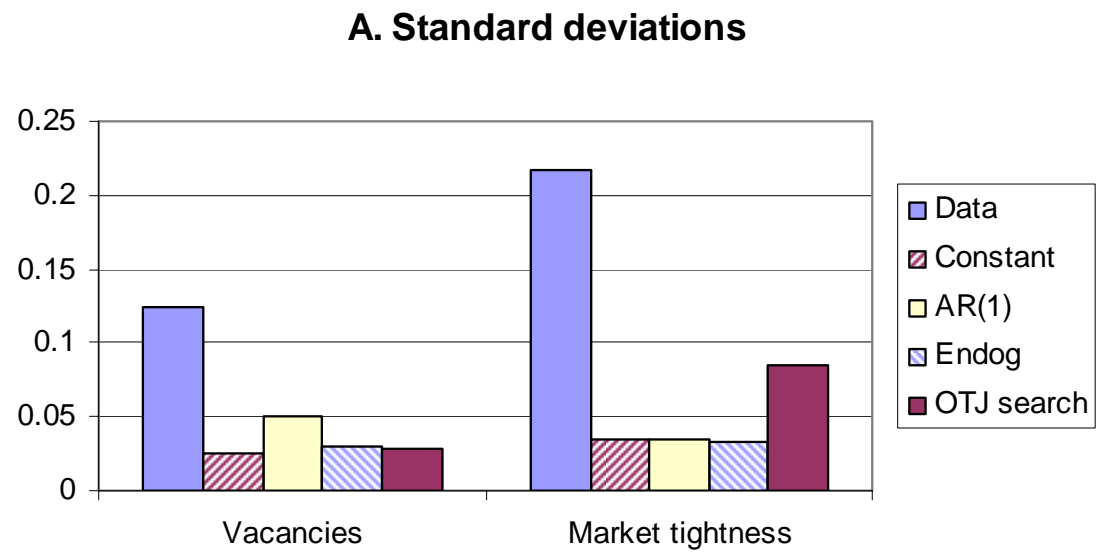

B. Productivity correlations

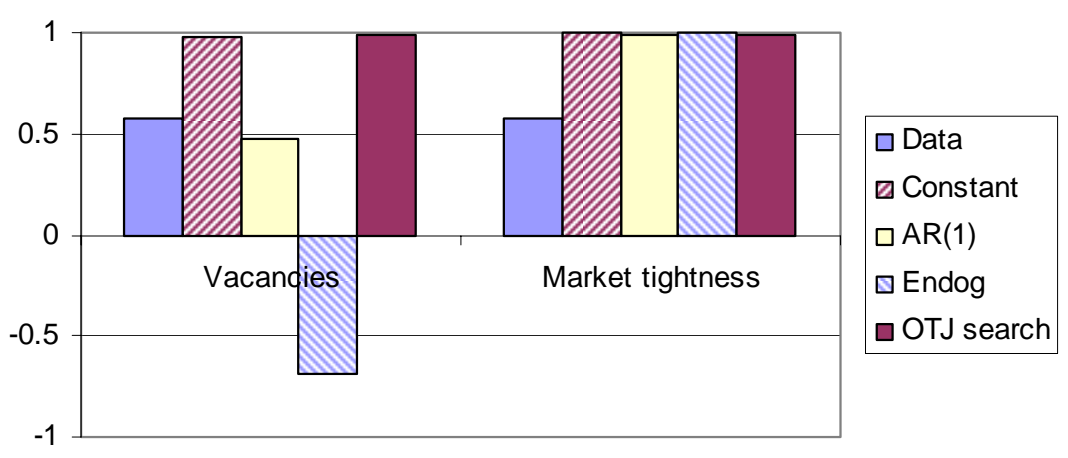

\section{Productivity elasticities}

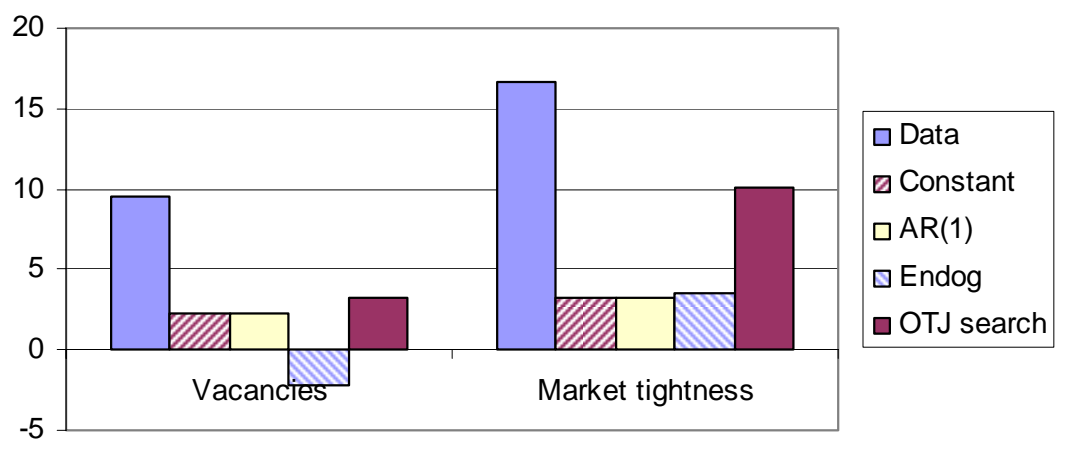


Figure 4. Contemporaneous correlations

A. Unemployment and vacancies

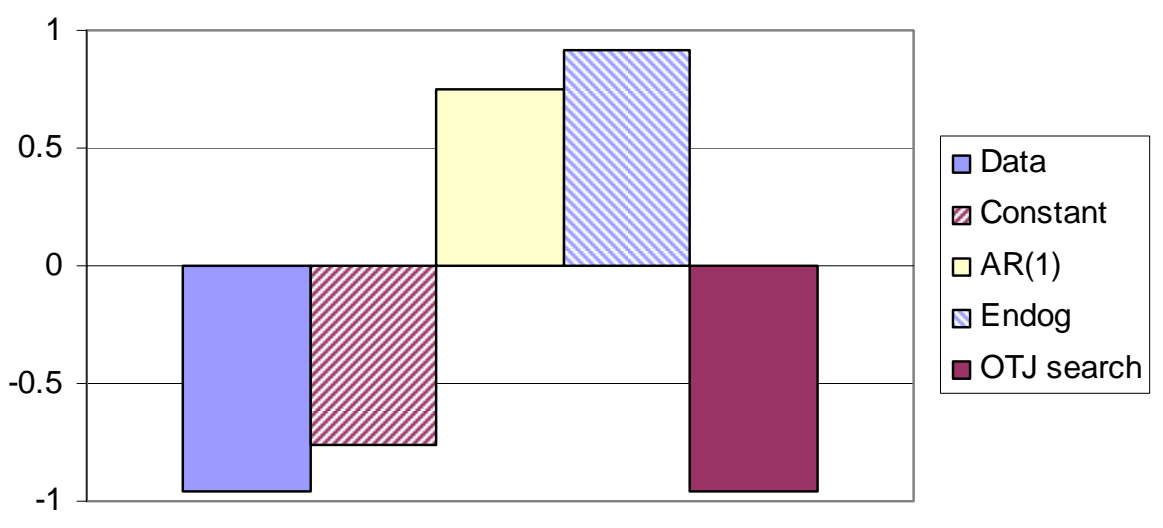

B. Job finding and separation rates

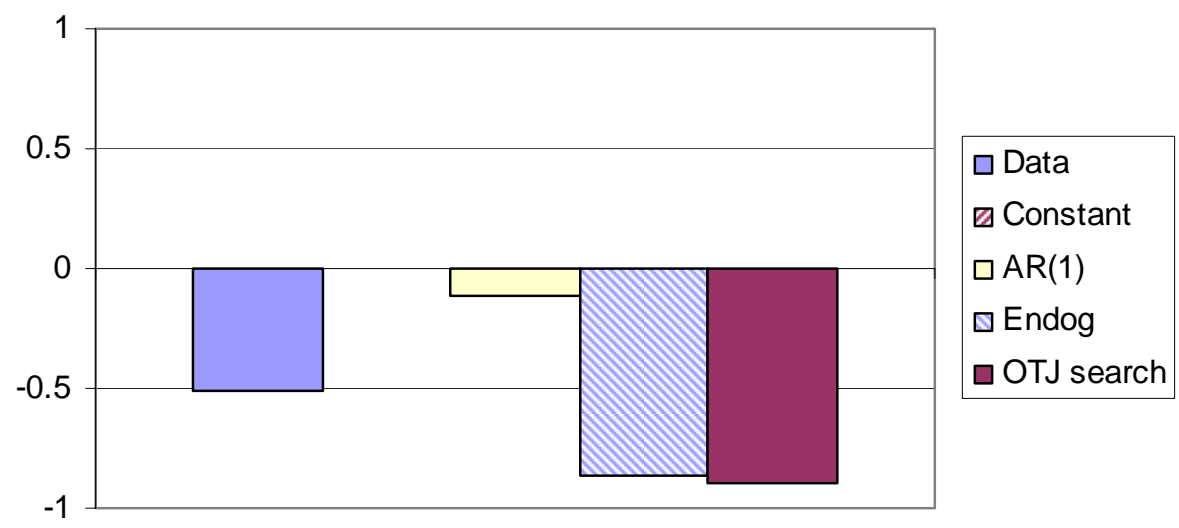


Figure 5. Cross elasticities with productivity: Unemployment and worker transition rates

\section{A. Unemployment}

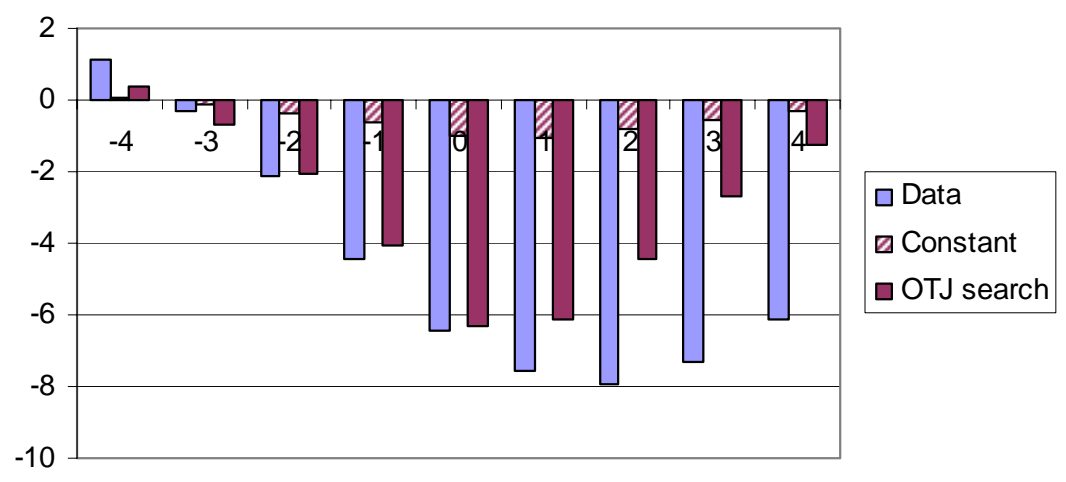

\section{B. Job finding rate}

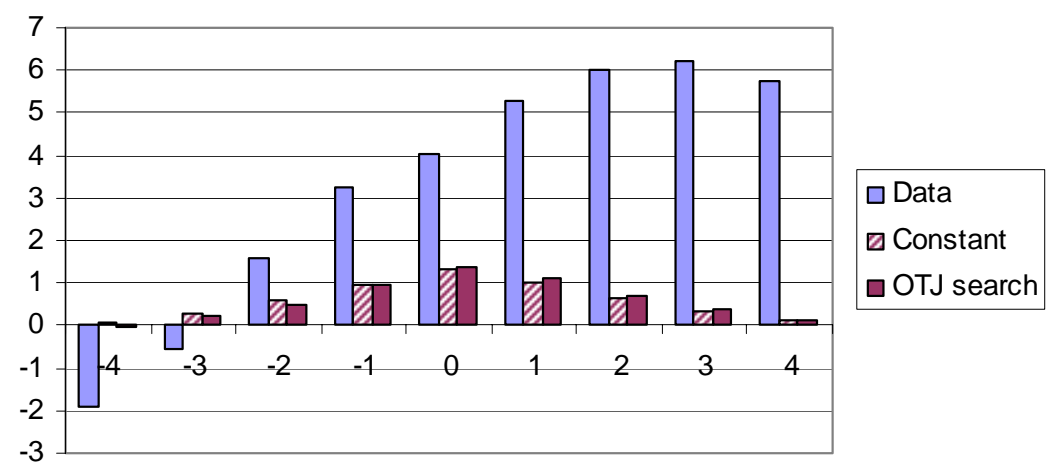

C. Separation rate

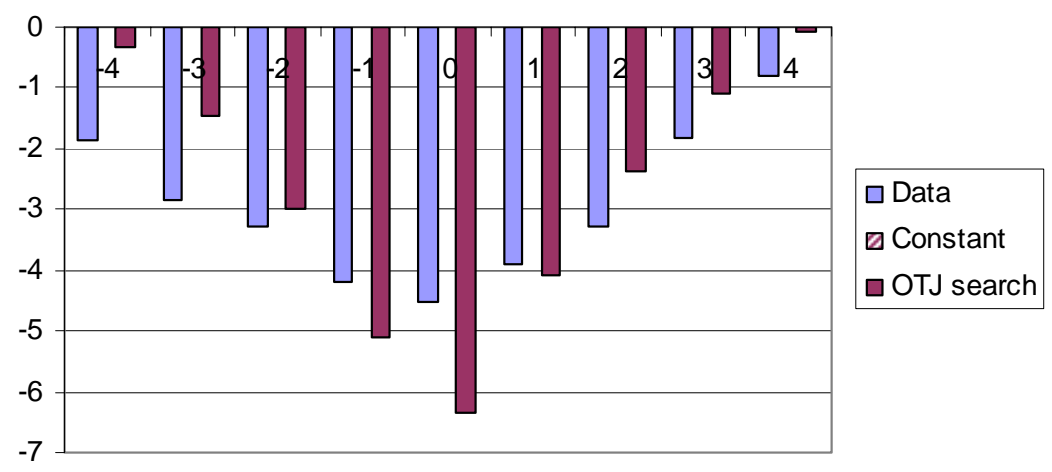


Figure 6. Cross elasticities with productivity: Worker flows

\section{A. UE flows}

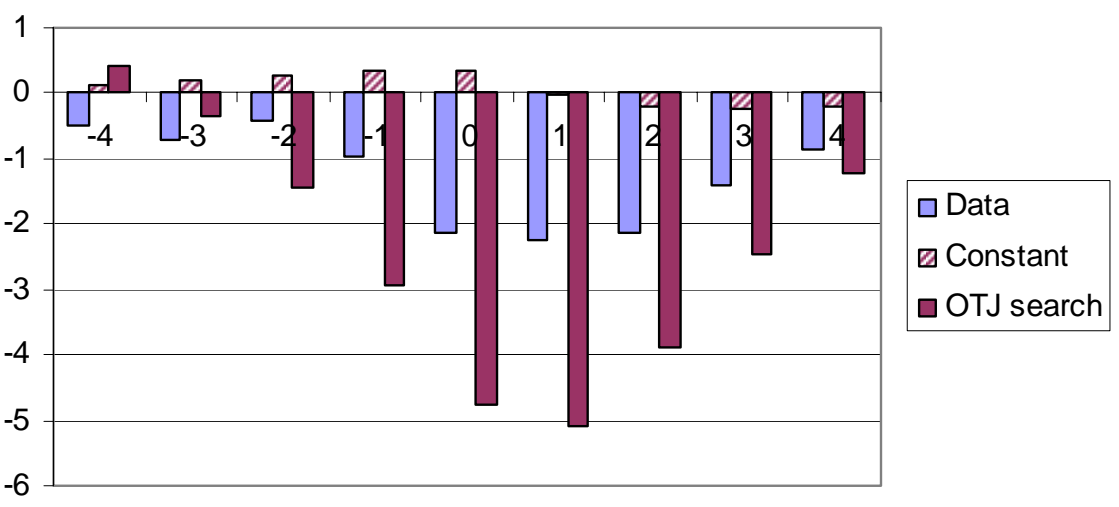

B. EU flows

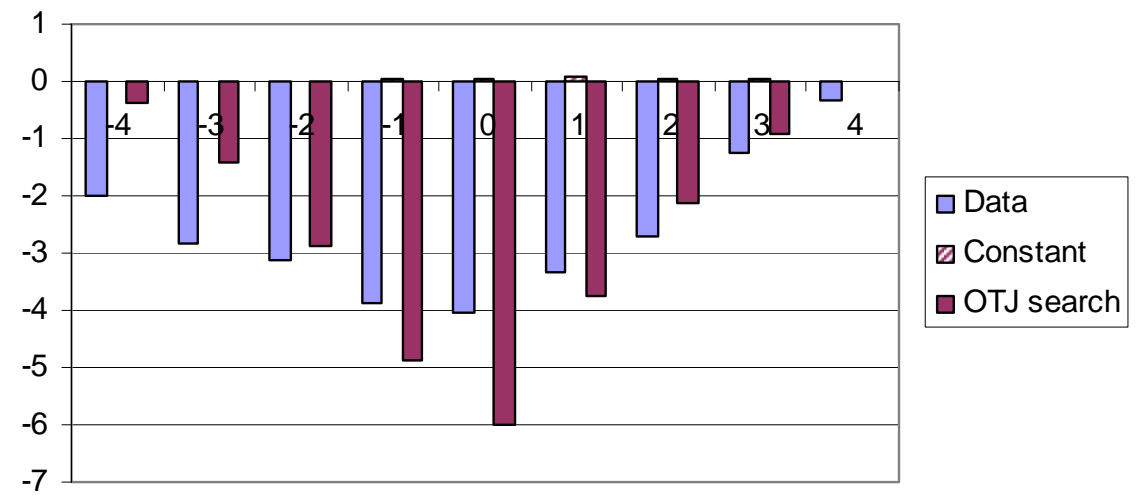


Figure 7. Cross elasticities with productivity:

Vacancies and market tightness

\section{A. Vacancies}

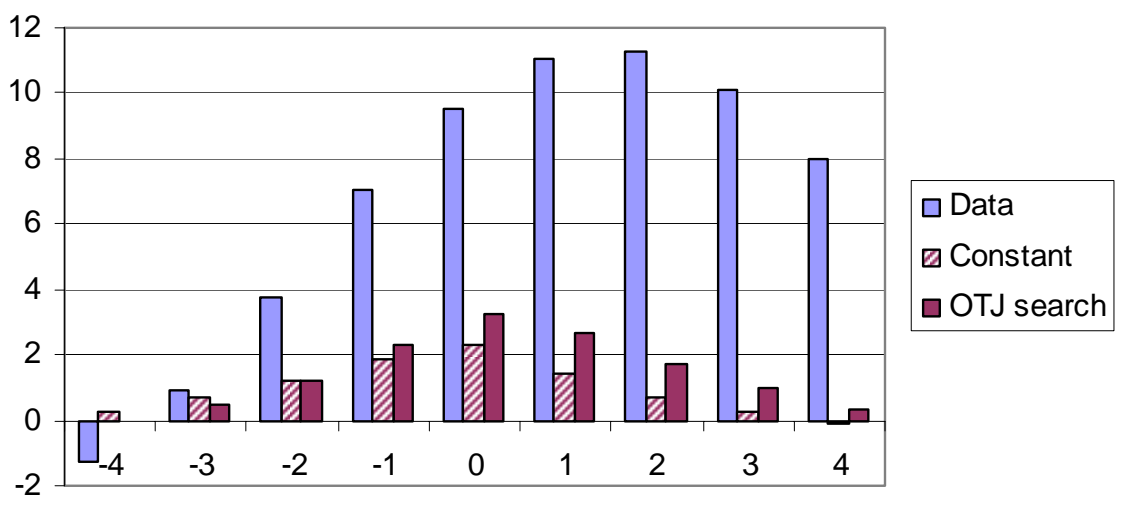

B. Market tightness

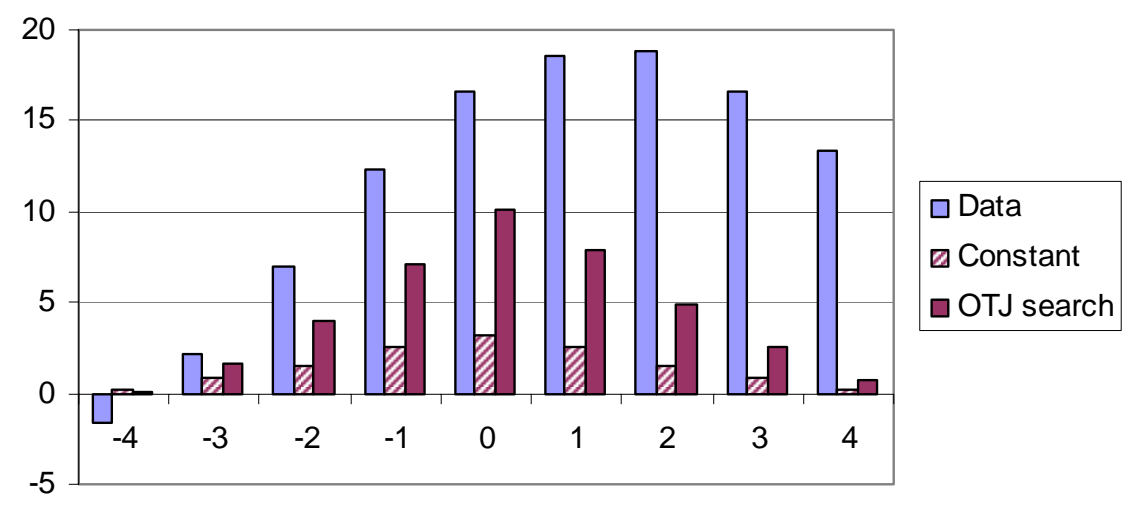


Figure 8. Cross correlations

\section{A. Unemployment and vacancies}

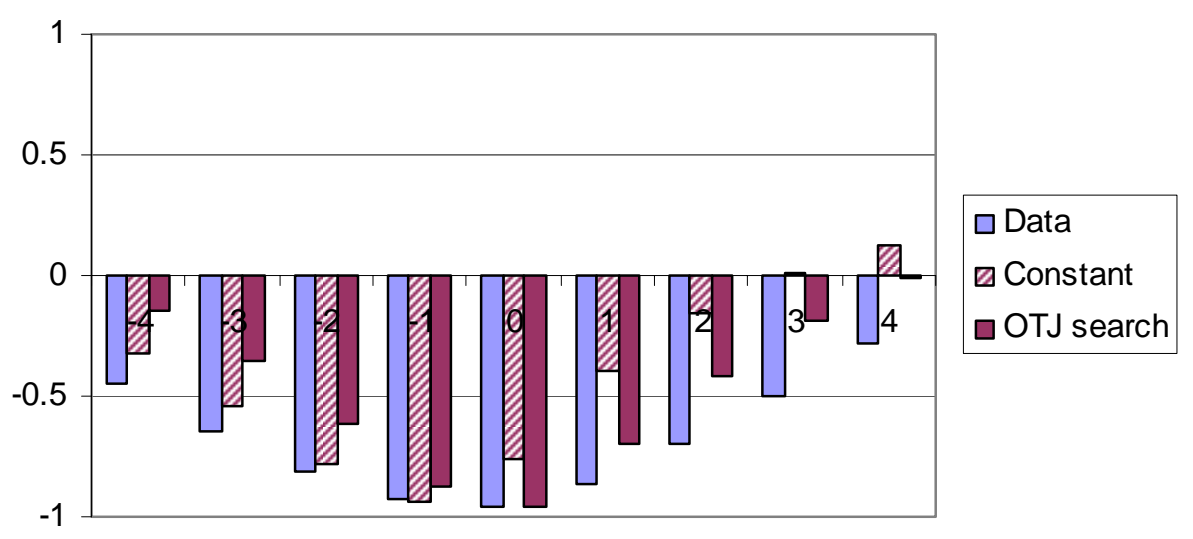

B. Job finding and separation rates

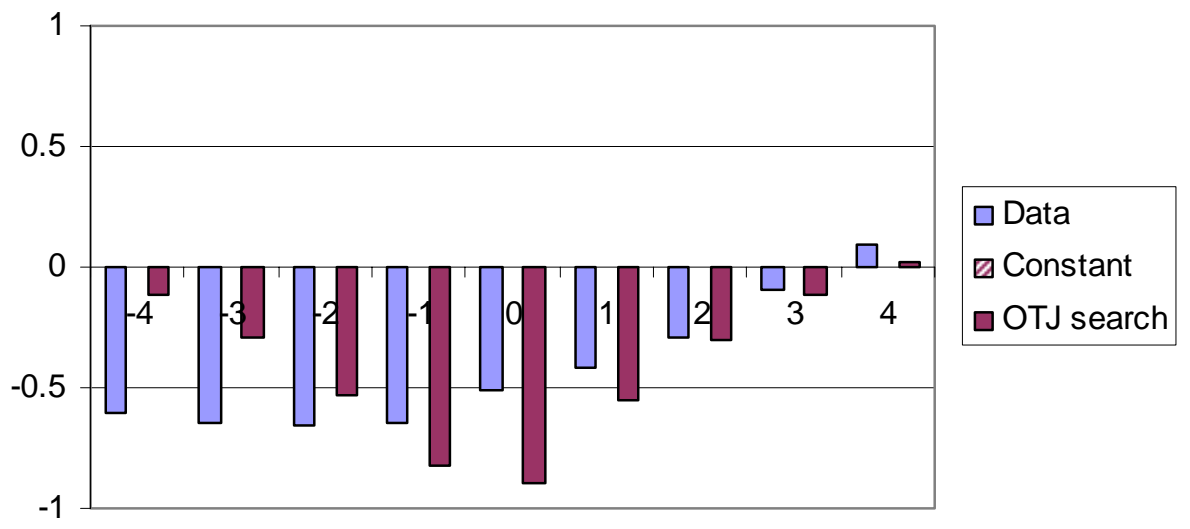


Figure 9. Unemployment and worker transition rates: Standard and HM calibrations

\section{A. Standard deviations}

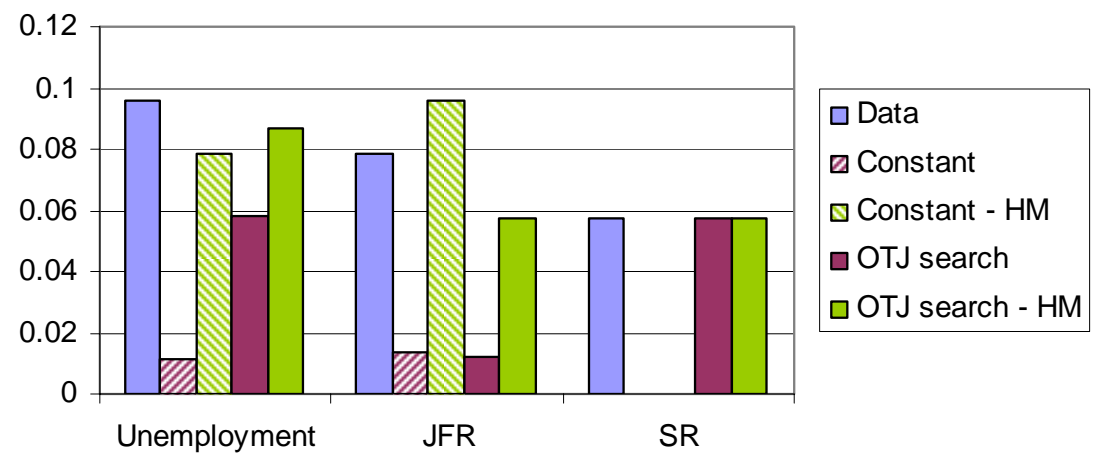

\section{B. Productivity correlations}

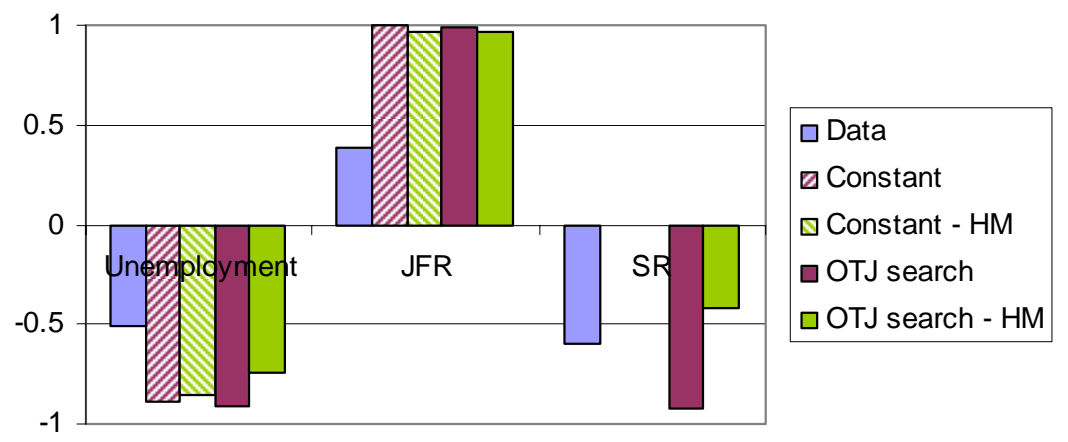

\section{Productivity elasticities}

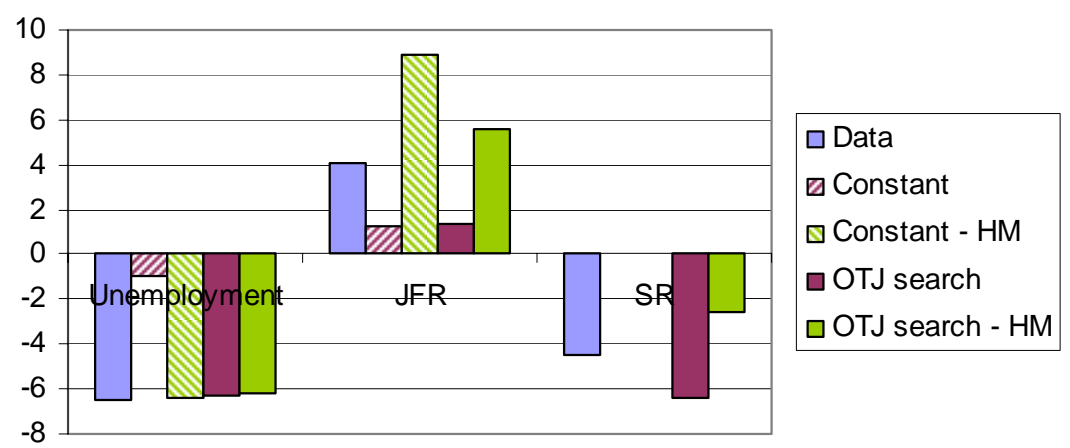


Figure 10. Worker flows:

Standard and HM calibrations

\section{A. Standard deviations}

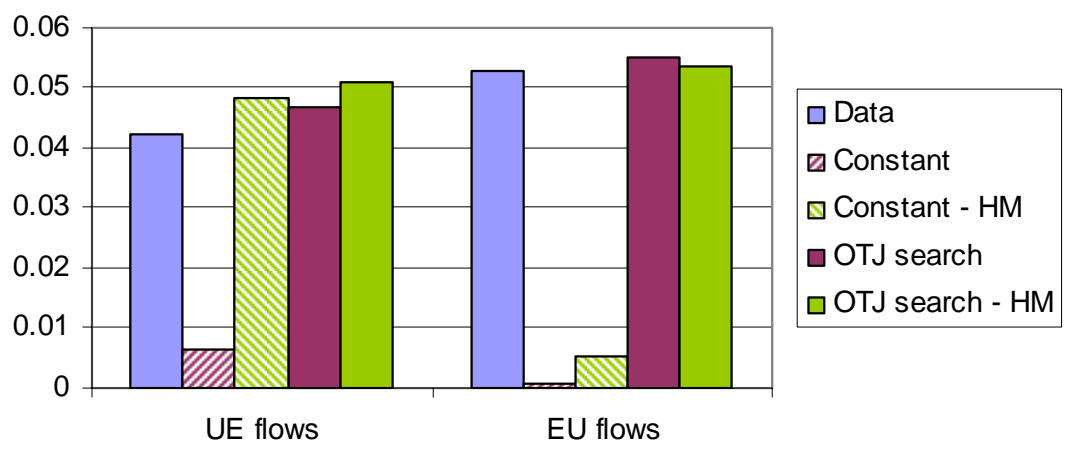

\section{B. Productivity correlations}

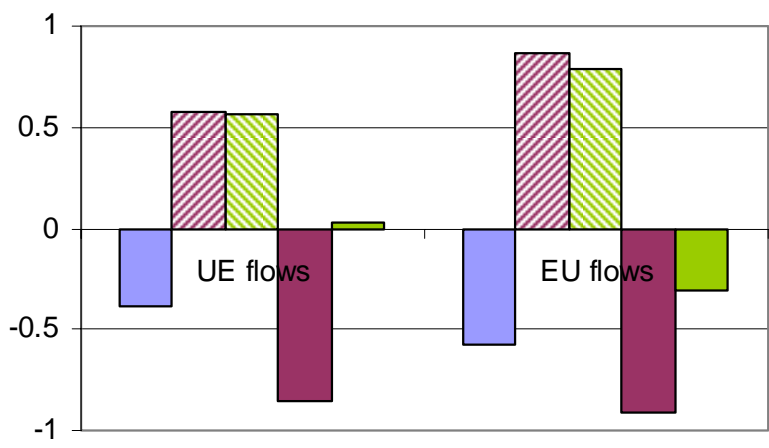

\section{Productivity elasticities}

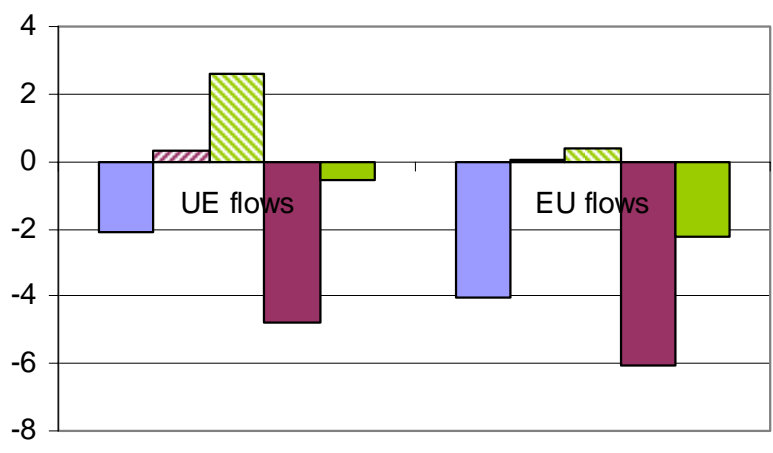


Figure 11. Vacancies and market tightness:

Standard and HM calibrations

\section{A. Standard deviations}

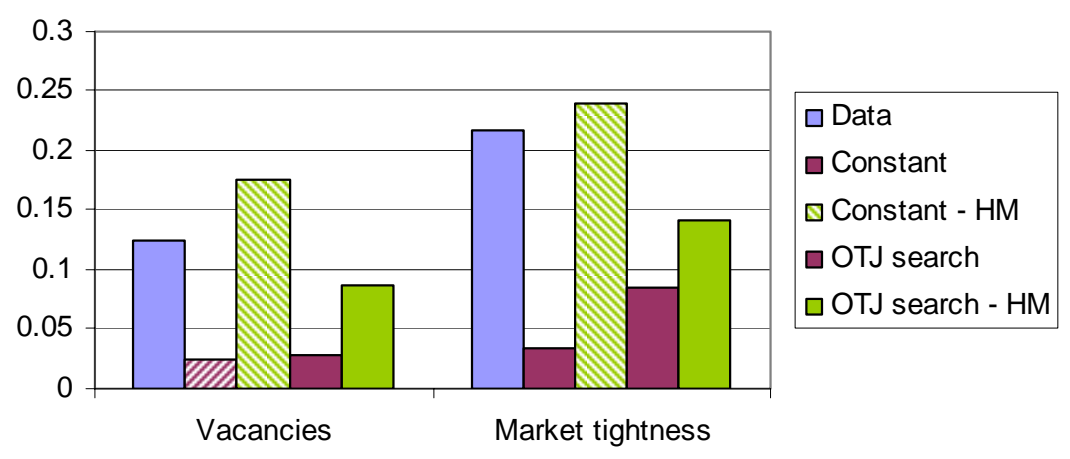

B. Productivity correlations

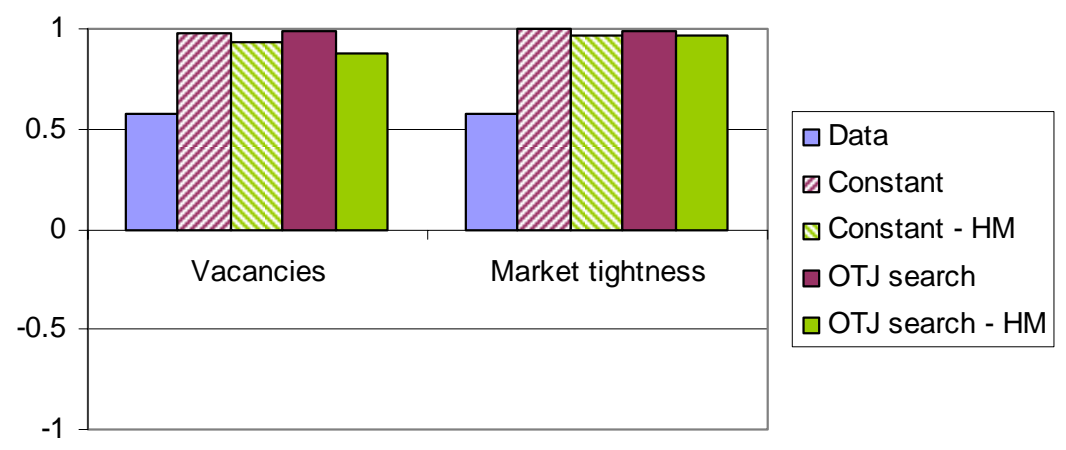

\section{Productivity elasticities}

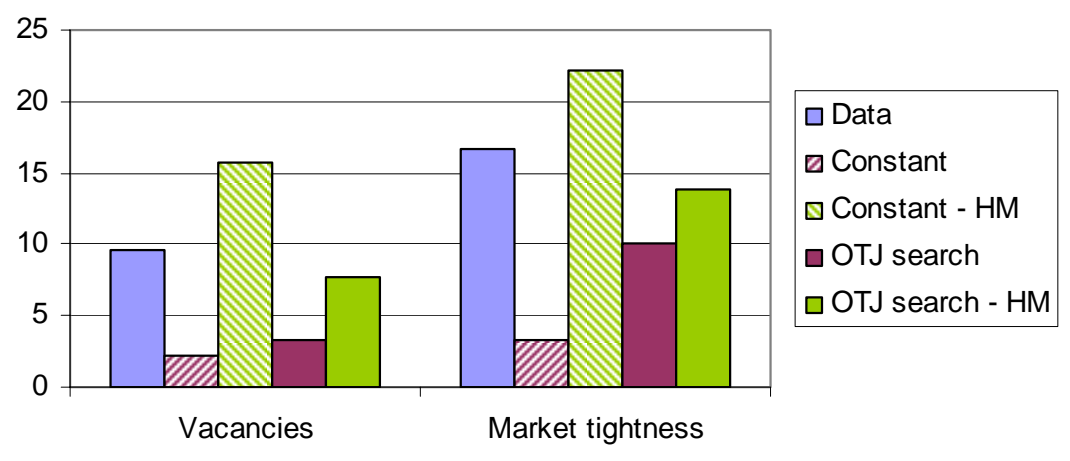


Figure 12. Contemporaneous correlations:

Standard and HM calibrations

\section{A. Unemployment and vacancies}

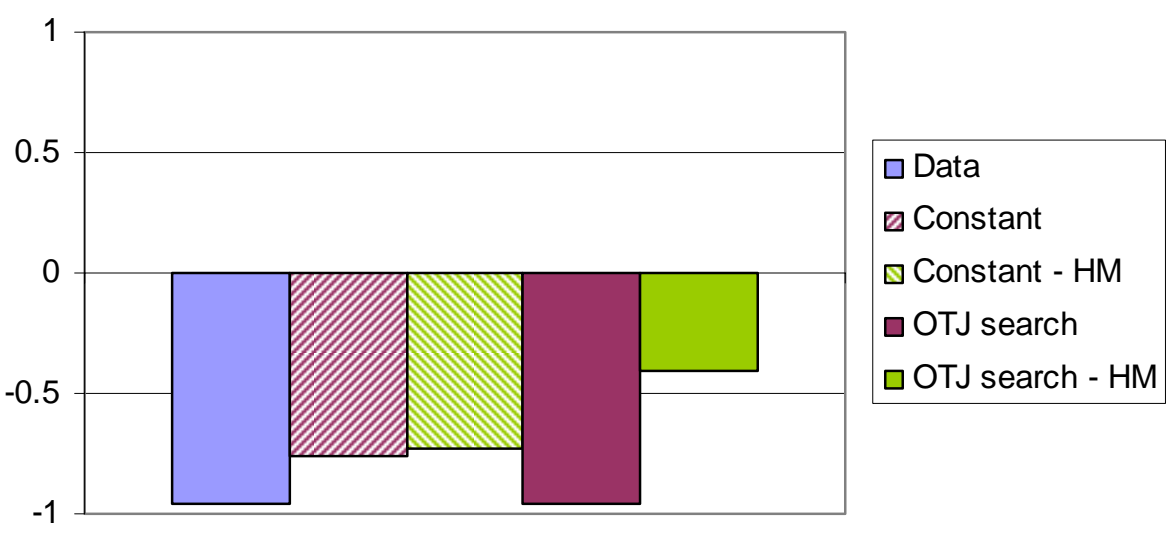

\section{B. Job finding and separation rates}

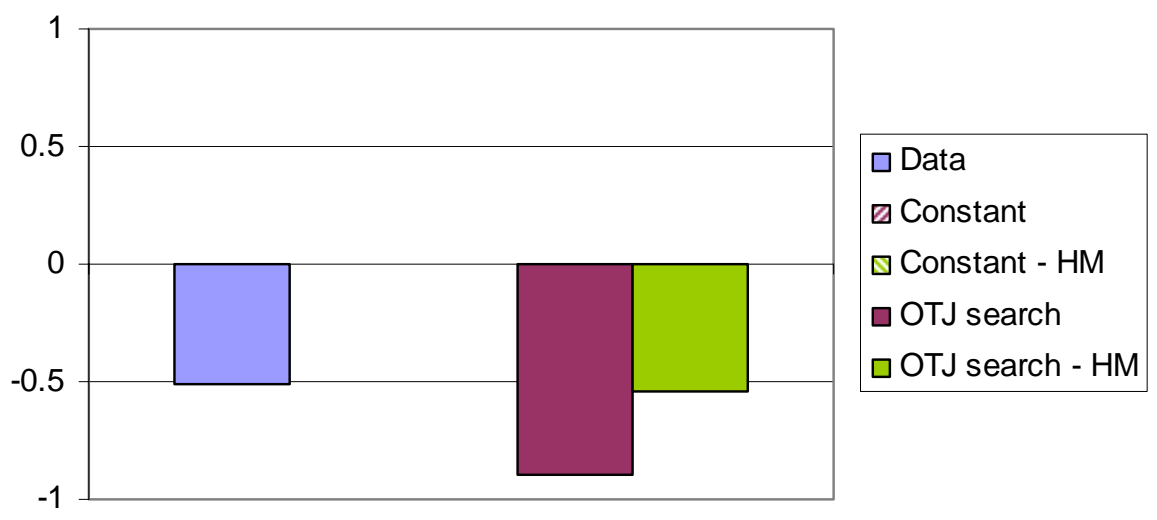

